\title{
Cell voltage model for Li-Bi liquid metal batteries
}

\author{
Norbert Weber ${ }^{\mathrm{a}, *}$, Carolina Duczek ${ }^{\mathrm{a}}$, Gerrit M. Horstmann ${ }^{\mathrm{a}}$, Steffen \\ Landgraf $^{\mathrm{a}}$, Michael Nimtz ${ }^{\mathrm{a}}$, Paolo Personnettaz ${ }^{\mathrm{a}}$, Tom Weier ${ }^{\mathrm{a}}$, Donald R. \\ Sadoway ${ }^{\mathrm{b}}$ \\ ${ }^{a}$ Helmholtz-Zentrum Dresden - Rossendorf, Bautzner Landstr. 400, 01328 Dresden, \\ Germany \\ ${ }^{b}$ Department of Materials Science and Engineering, Massachusetts Institute of Technology, \\ 77 Massachusetts Avenue, Cambridge, MA 02139-4307, USA
}

\begin{abstract}
Lithium-bismuth bimetallic cells are amongst the best explored liquid metal batteries. A simple and fast quasi-one-dimensional cell voltage model for such devices is presented. The equilibrium cell potential is obtained from a complex two-dimensional fit of data drawn from multiple studies of equilibrium cell potential and rendered congruent with the phase diagram. Likewise, several analytical and fit functions for the ohmic potential drop across the electrolyte are provided for different battery geometries. Mass transport overpotentials originating from the alloying of $\mathrm{Li}$ into $\mathrm{Bi}$ are modelled by solving a diffusion equation, either analytically or numerically, and accounting for the volume change of the positive electrode. The applicability and limitations of the model are finally illustrated in three distinct experimental settings.
\end{abstract}

Keywords: liquid metal battery, diffusion, volume change, cell voltage model

\section{Introduction}

The ever increasing deployment of highly fluctuating renewable energies requires stationary energy storage to balance energy production and consumption. Offering extreme current densities as well as an extended lifetime at a competitive price, liquid metal batteries (LMBs) have been discussed as an ideal

* Corresponding author. Helmholtz-Zentrum Dresden - Rossendorf, Bautzner Landstr. 400, 01328 Dresden, Germany. E-mail address: norbert.weber@hzdr.de (N. Weber)

Preprint submitted to Applied Energy

January 25, 2022 
candidate for large scale energy storage [1]. While the heavy positive electrode metal (e.g. Bi, cathode at discharge) forms the bottom layer, a light negative electrode metal (e.g. Li, anode at discharge) is usually soaked into a Ni foam - as illustrated in figure 1. Both liquid electrodes are separated by an ionconducting (e.g. $\mathrm{Li}^{+}$) molten salt mixture. At discharge, the negative electrode metal is oxidised, crosses the electrolyte layer in ionic form, is then reduced at the interface of the lower electrode and finally alloys with the positive electrode metal.

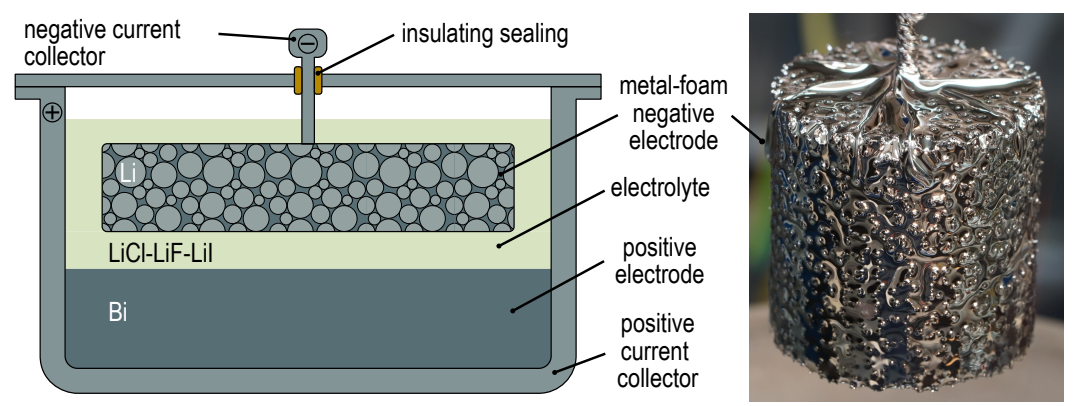

Figure 1: Sketch (not to scale) of an LMB with a metal foam negative electrode (left) and Ni foam filled with $\mathrm{Li}$ (right).

Between the many possible electrode-combinations, the Li ||Bi cell is one of the best explored systems, as it provides unique benefits compared to other chemistries. Table 1 gives an overview on the cells and their properties built in the past. On the one hand, Li has a low solubility in its molten salts, which ensures a very high coulombic efficiency by reducing self-discharge [2]. On the other hand, the Li||Bi cell potentially can be operated in the two-phase area as well, which distinguishes it from many other systems, as, e.g. Na||Bi or $\mathrm{Ca}|| \mathrm{Bi}[2]$. When $\mathrm{Li}$ is alloyed into Bi during discharge, the intermetallic phase $\mathrm{Li}_{3} \mathrm{Bi}$ will form should a certain Li-concentration be exceeded locally. The intermetallic phase would then float on top of the Bi-electrode due to its lower density [2]. $\mathrm{As} \mathrm{Li}_{3} \mathrm{Bi}$ is an electric semiconductor and has a very high diffusivity for $\mathrm{Li}[2,3]$, the cells can be operated in a semi-solid state enabling a very high Liutilisation of more than $90 \%$. Although the intermetallic phase dissolves slightly 
Table 1: Properties of experimental Li||Bi cells: energy efficiency $\eta$, coulombic efficiency $\eta_{\mathrm{c}}$, operating temperature $T_{\mathrm{o}}$, maximum current density $j$, cell potential $E$ at a Li molar fraction

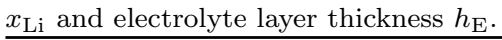

\begin{tabular}{|c|c|c|c|c|c|c|c|c|c|c|}
\hline \multirow[t]{2}{*}{ electrolyte } & $\eta$ & $\eta_{\mathrm{c}}$ & life time & $T_{\mathrm{O}}$ & price & $j$ & $E$ & ${ }^{x} \mathrm{Li}$ & $h_{\mathrm{E}}$ & source \\
\hline & \multicolumn{2}{|c|}{$\%$} & cycles & ${ }^{\circ} \mathrm{C}$ & $\$ / \mathrm{kWh}$ & $\mathrm{A} / \mathrm{cm}^{2}$ & $\mathrm{~V}$ & & $\mathrm{~mm}$ & \\
\hline & & & & 527 & & & 0.81 & 0.2 & & {$[11$, p. 154$]$} \\
\hline & & & & 527 & & & 0.9 & & & {$[9$, p. 186$]$} \\
\hline & & & & & & & 0.931 & & & {$[12$, p. 119$]$} \\
\hline $\mathrm{LiCl}-\mathrm{KCl}$ & & & & 489 & & & 0.93 & & $15-33$ & {$[11$, p. 155$]$} \\
\hline $\mathrm{LiCl}-\mathrm{KCl}$ & & & & 489 & & 0.8 & 0.93 & 0 & & {$[13$, p. 113$]$} \\
\hline $\mathrm{LiCl}-\mathrm{KCl}$ & & & & 352 & & & 0.9 & & & {$[14$, p. 216$]$} \\
\hline $\mathrm{LiCl}-\mathrm{KCl}$ & & & & 400 & & 1.6 & 0.94 & & & [15] \\
\hline $\mathrm{LiCl}-\mathrm{KCl}$ & & & & 550 & & 6 & & & & {$[16]$} \\
\hline LiCl-LiF & & & & $500-850$ & & & 0.96 & 0.05 & & {$[17]$} \\
\hline LiCl-LiF & & & & $500-850$ & & & 0.96 & 0.05 & & {$[11$, p. 109$]$} \\
\hline LiCl-LiF & 70 & 99.7 & 1000 & 550 & $220-242$ & 1.25 & 0.96 & 0 & 10 & {$[2]$} \\
\hline $\mathrm{LiCl}-\mathrm{LiF}$ & & & & $500-850$ & & & 0.96 & 0.05 & & [18] \\
\hline $\mathrm{LiCl}-\mathrm{LiF}$ & & & & $477-880$ & & & 0.96 & 0.05 & & {$[12$, p. 118$]$} \\
\hline LiCl-LiF & & & & 550 & & 6 & & & & {$[16]$} \\
\hline LiCl-LiF & & & & $510-560$ & & & 0.96 & 0.03 & & [19] \\
\hline LiCl-LiF & & & & $500-717$ & & & & & & {$[20]$} \\
\hline LiCl-LiF-LiI & & & & $380-485$ & & 2.2 & 1.4 & 0 & 3.4 & {$[21]$} \\
\hline LiCl-LiF-LiI & & & & 485 & & $>1.8$ & 1.25 & 0 & 3.4 & {$[22$, p. 187$]$} \\
\hline LiCl-LiF-LiI & & & & 500 & & 2.2 & 0.9 & & & {$[23$, p. 111$]$} \\
\hline LiCl-LiF-LiI & & & & 460 & & & & & & [24] \\
\hline
\end{tabular}

in molten salts, which is well visible due to its red colour [4-6] (see image in [7]), the solubility and irreversible Bi-transport to the positive electrode is rather low [8-10].

Based on the good availability of material properties and experimental data for Li||Bi cells, a number of modelling works have been performed for the system [25]. Especially fluid dynamic phenomena, such as the sloshing instability [2628], electro-vortex flow [29], thermal convection [30-32], Marangoni convection [32], mass transfer [33-35] and solutal convection [24, 36, 37] have been studied. In addition, one-dimensional electrochemical models for $\mathrm{Mg}-\mathrm{Sb}$ [38] and $\mathrm{Li}$ Bi $[24,38]$ cells have been developed [38], three-dimensional models for masstransport overpotentials by various authors $[24,39]$ and a 3D cell voltage model by Weber et al. [40, 41].

All of these models have certain advantages and disadvantages: while the three-dimensional models are very accurate, they cannot be used for applications such as battery management systems as they are computationally too expensive. 
The one-dimensional models are fast, but sometimes "oversimplified", which limits their application to only certain use cases. The aim of the present paper is to discuss and classify the various effects determining the cell voltage of $\mathrm{Li}|| \mathrm{Bi}$ LMBs in order to develop a quasi-one-dimensional model, which unites the advantages of the 3D (accuracy) and 1D-models (speed). Being as simple as possible and as complex as necessary, it shall account for all relevant effects to be employed for a broad range of applications, as outlined in section 5.1.

\section{Model}

\subsection{Overview}

The quasi-one-dimensional model describes the cell voltage as function of current and time by first computing the equilibrium cell potential and then subtracting the various overpotentials. Moreover, a diffusion equation for the Li-concentration in $\mathrm{Bi}$ is solved in the positive electrode to obtain (after a conversion) the Li molar fraction, which is needed to calculate the equilibrium cell potential. Finally, volume changes of the positive electrode and electrolyte layer are taken into account when solving the diffusion equation and when determining the ohmic losses.

\subsection{Open circuit potential}

The equilibrium cell potential $E_{\text {eq }}$ can be described by the Nernst equation as $[1]$

$$
E_{\text {eq }}=-\frac{\mathrm{R} T}{\nu_{e} \mathrm{~F}} \ln \left(a_{\mathrm{Li}(\mathrm{Bi})}\right)
$$

with $\mathrm{R}$ denoting the universal gas constant, $T$ the temperature in $\mathrm{K}, \nu_{e}$ the number of exchanged electrons and $\mathrm{F}$ the Faraday constant. Generally, the

activity $a_{\mathrm{Li}(\mathrm{Bi})}$ of $\mathrm{Li}$ in $\mathrm{Bi}$ or $E_{\text {eq }}$ itself might be fitted, using e.g. data listed in table 5 . We take the latter option leading to a molar fraction and temperature dependent equilibrium cell potential in the liquid phase of

$$
E_{\mathrm{lq}}=10^{-3}\left(o+p \ln (x)+T\left(a \ln (x)+b x+c x^{2}+d x^{3}+e x^{4}+f x \ln (x)\right)\right)
$$


with $T$ in $\mathrm{K}$ and

$$
\begin{aligned}
& o=786.66, \quad p=-6.10, \quad a=-0.07, \quad b=4.66, \\
& c=-16.50, \quad d=28.96, \quad e=-23.01, \quad f=1.75 .
\end{aligned}
$$

The obtained fit function inter- and extrapolates the measurement values of $[17,19,20]$, and is valid for temperatures between $415^{\circ} \mathrm{C}$ and approximately $600{ }^{\circ} \mathrm{C}$, with higher errors up to $900^{\circ} \mathrm{C}$.

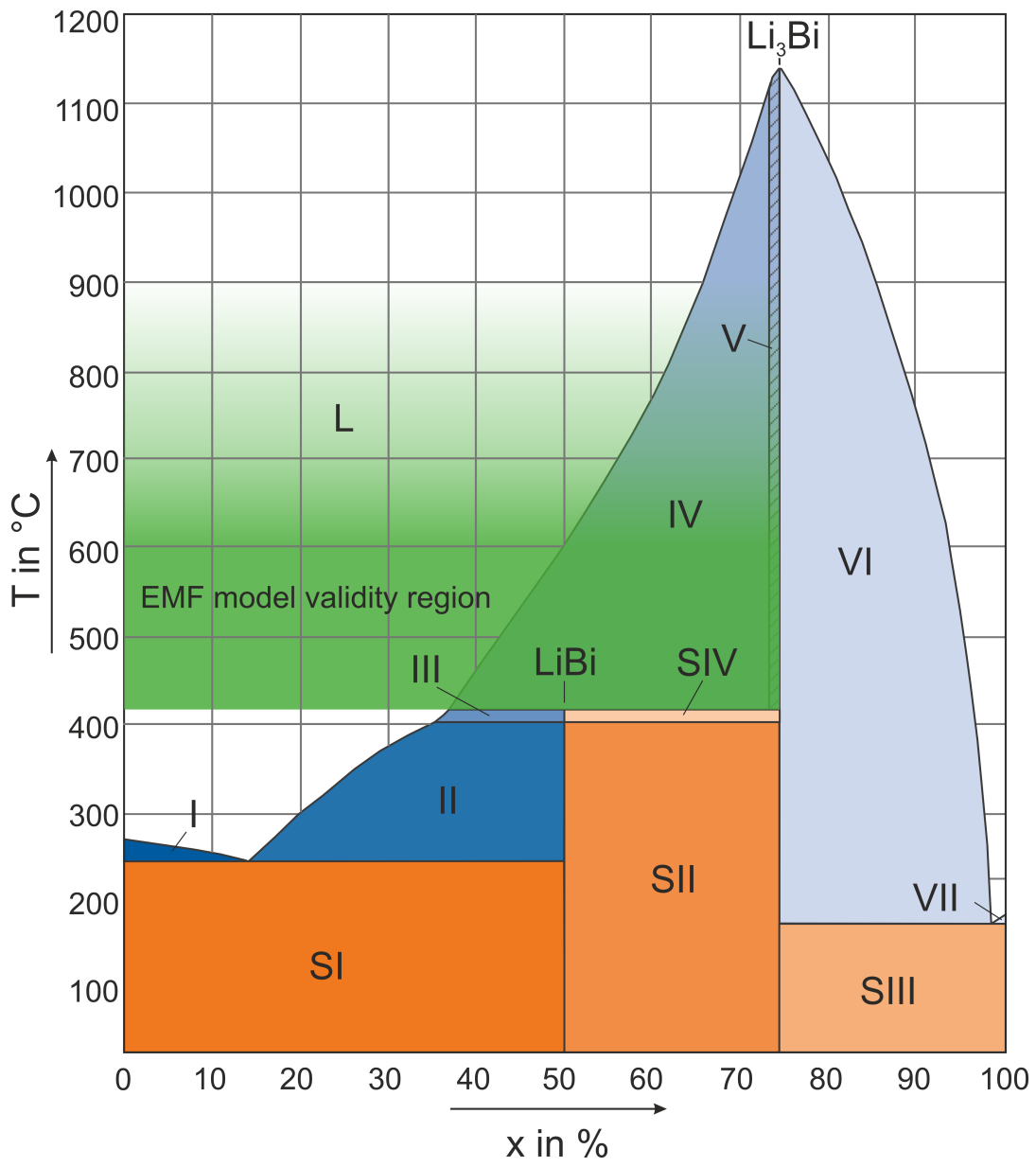

Figure 2: Phase diagram of $\mathrm{Li}-\mathrm{Bi}$ according to [42] with different cell voltage areas and the region of validity shaded in green. L denotes the liquid phase.

Once reaching the two-phase area (figure 2), the cell potential will stay 
constant, when forming the intermetallic phase $\mathrm{Li}_{3} \mathrm{Bi}$. The modelled equilibrium cell potential $E_{\text {eq }}$ reads therefore

$$
E_{\mathrm{eq}}= \begin{cases}E_{\mathrm{lq}} & \text { in the liquid area } \mathrm{L}, \\ E_{\mathrm{lq}}(x=0.01) & \text { in the liquid phase } \mathrm{L} \text { for } \mathrm{x}<0.01, \\ E_{\mathrm{lq}}\left(T_{\mathrm{lq}}\right) & \text { in region IV, } \\ E_{\mathrm{lq}}\left(T_{\mathrm{lq}}\right)\left(1-\frac{x-0.73}{0.75-0.73}\right) & \text { in region } \mathrm{V} .\end{cases}
$$

with $T_{\text {lq }}$ denoting the liquidus temperature in $\mathrm{K}$, obtained from the phase diagram [43] using a spline fit. The different phases and regions are listed in table 2 and are identified in the model using simple if-else statements as function of temperature and Li molar fraction.

Table 2: Phases present in the lithium-bismuth system. L denotes the liquid phase.

\begin{tabular}{|c|c|c|}
\hline region & phase & state \\
\hline $\mathrm{L}$ & $\mathrm{Li}+\mathrm{Bi}$ & liquid \\
\hline I & $\mathrm{Bi}+\mathrm{L}$ & two-phase \\
\hline II & L+LiBi (low temp.) & two-phase \\
\hline III & L+LiBi (high temp.) & two-phase \\
\hline IV & $\mathrm{L}+\mathrm{Li}_{3} \mathrm{Bi}$ & two-phase \\
\hline $\mathrm{V}$ & $\mathrm{L}+\mathrm{Li}_{3} \mathrm{Bi}$ (extended intermetallic) & two-phase \\
\hline VI & $\mathrm{Li}_{3} \mathrm{Bi}+\mathrm{L}$ & two-phase \\
\hline VII & $\mathrm{L}+\mathrm{Li}$ & two-phase \\
\hline SI & Bi+LiBi (low temp.) & solid solution \\
\hline SII & $\mathrm{LiBi}$ (low temp.) $+\mathrm{Li}_{3} \mathrm{Bi}$ & solid solution \\
\hline SIII & $\mathrm{Li}_{3} \mathrm{Bi}+\mathrm{Li}$ & solid solution \\
\hline SIV & $\mathrm{LiBi}$ (high temp.) $+\mathrm{Li}_{3} \mathrm{Bi}$ & solid solution \\
\hline
\end{tabular}

Regions not included in the cell voltage model are the phases with high lithium fractions $(x>0.75)$ and the liquid and solid phases below $415{ }^{\circ} \mathrm{C}$. While sufficient datapoints were available for higher temperatures $\left(450{ }^{\circ} \mathrm{C}\right.$ to $\left.900^{\circ} \mathrm{C}\right)$, only few datasets exist down to $380^{\circ} \mathrm{C}$ for the two-phase region [44]. The lowtemperature liquid and bismuth-rich phases are not represented in available 
measurement data. Therefore, we model the electromotive force as follows in these phases:

$$
E=0 \text { in regions I-III, SI-SIV, VI and VII. }
$$

The resulting equilibrium cell potential as function of the Li molar fraction and temperature is exemplarily illustrated in figure 3.

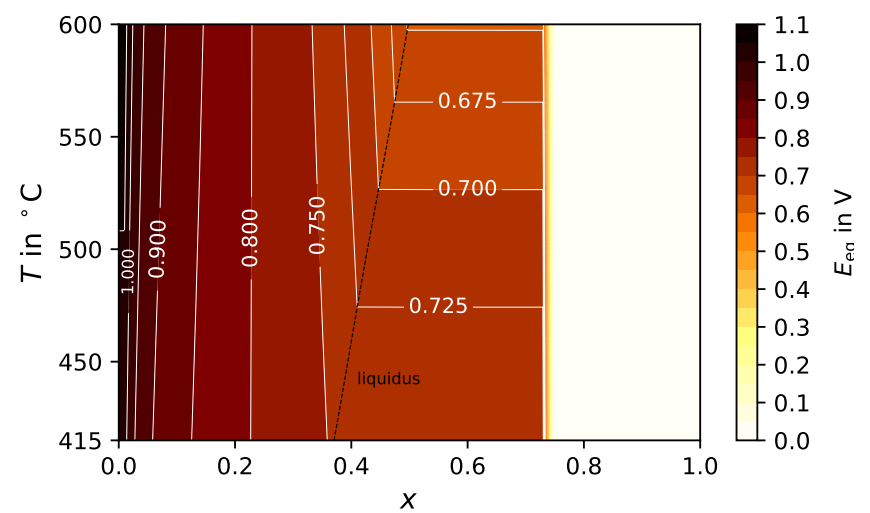

Figure 3: Equilibrium cell potential fitted with experimental data from [17, 19, 20].

\subsection{Overpotentials}

\subsubsection{Activation losses}

The activation overpotential $\eta_{\text {act }}$ can be described by the Butler-Volmer equation as $[45-47]$

$$
j=j_{0} \cdot\left(\exp \left(\frac{\alpha n \mathrm{~F}}{\mathrm{R} T} \eta_{\text {act }}\right)-\exp \left(-\frac{(1-\alpha) n \mathrm{~F}}{\mathrm{R} T} \eta_{\text {act }}\right)\right)
$$

with $j$ denoting the current density, $j_{0}$ the exchange current density, $\alpha$ the charge transfer coefficient and $n$ the reaction order of the rate limiting step. For a small overpotential, i.e. if

$$
\eta_{\text {act }}<\mathrm{RT} / \mathrm{F} \approx 66 \mathrm{mV} \quad\left(\text { at } 500^{\circ} \mathrm{C}\right)
$$

the Butler-Volmer equation can be linearised by approximating $\exp (y)$ as $1+y$, which leads to [45]

$$
j=j_{0} \frac{n \mathrm{~F}}{\mathrm{R} T} \eta_{\text {act }} .
$$


Newhouse measured concentration dependent exchange current densities at the positive electrode between 4 and $50 \mathrm{~A} / \mathrm{cm}^{2}[38,48]$. Using both limiting values, we find for a typical temperature of $500{ }^{\circ} \mathrm{C}$ an activation loss of

$$
\eta_{\text {act }}=\left\{\begin{array}{lll}
0.0170 \cdot j\left(\mathrm{~A} / \mathrm{cm}^{2}\right) & \text { for } & j_{0}=4 \mathrm{~A} / \mathrm{cm}^{2} \\
0.0013 \cdot j\left(\mathrm{~A} / \mathrm{cm}^{2}\right) & \text { for } & j_{0}=50 \mathrm{~A} / \mathrm{cm}^{2}
\end{array},\right.
$$

which would result in a voltage loss of $0.4 \ldots 5 \mathrm{mV}$ for a typical current density of $0.3 \mathrm{~A} / \mathrm{cm}^{2}$ and to $1.3 \ldots 17 \mathrm{mV}$ for a high current density of $1 \mathrm{~A} / \mathrm{cm}^{2}$. Assuming that the exchange current densities are similar at the negative electrode, the activation losses appear to be minuscule compared to the ohmic overpotential. In line with Newhouse' conclusion [48], the activation losses are neglected in the present model.

\subsubsection{Ohmic overpotential}

The ohmic loss represents typically the most important overpotential of an LMB. In general, its value can either be measured or calculated. As the electrolyte conductivity is four orders of magnitude lower than those of the metals, only ohmic losses in the molten salt will be accounted for. In the most simple case, if positive and negative electrode have the same cross section area $S$, the voltage loss is simply

$$
\eta_{\Omega}=I R=I \frac{H}{S \sigma}
$$

with $I$ denoting the cell current, $R$ the electrolyte resistance, $H$ its thickness, $\sigma$ the electrical conductivity and $S$ the surface area.

However, in real cells, often a metal foam is used to contain the molten Li. As illustrated in figure 4, the negative electrode has then a smaller diameter than the positive electrode. Additionally, the porous structure of the foam may lead to an additional constriction resistance. However, as long as the pores at the interface are fully filled with molten Li and the ligaments are covered by it, i.e. as long as the cell is not fully discharged, such a constriction resistance might be neglected.

For a cylindrical cell or square cell, as shown in figure 4, a simple Laplace equation can be solved in the electrolyte to obtain an estimate of the ohmic 

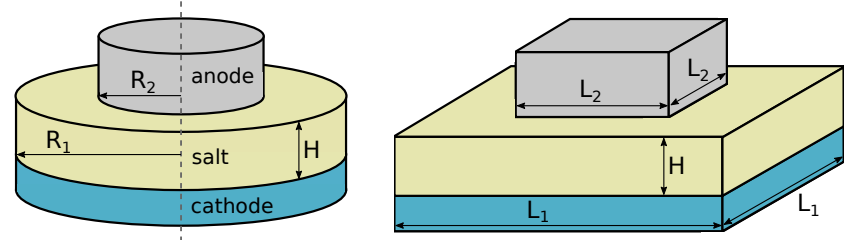

Figure 4: Sketch of a cylindrical (left) and rectangular (right) LMB using a metal-foam negative electrode current collector.

potential drop. Considering the comparably low conductivity of the salt, isopotential boundary conditions are expected to provide the most realistic results. Solving this equation for a rotational-symmetric cylindrical geometry as well as a square cell with OpenFOAM [49] for a large parameter set and subsequent fitting, we obtain the ohmic overpotential as function of current, radii and layer height - as outlined in Appendix A.2 and Appendix A.3.

Alternatively, the Laplace equation can be solved analytically for a cylindrical cell using certain assumptions and simplifications - as explained in Appendix A.1. This leads to an explicit expression in terms of an infinite series:

$$
\begin{aligned}
\eta_{\Omega} & =\frac{I H}{\sigma \pi R_{1}^{2}} \\
& +\sum_{n=1}^{\infty} \frac{I J_{1}\left(\kappa_{0 n}\right)}{\sigma \pi \epsilon_{0 n}^{2} R_{2}} \tanh \left(\frac{\epsilon_{0 n}}{R_{1}} \frac{H}{2}\right) \frac{\pi H_{0}\left(\kappa_{0 n}\right) J_{1}\left(\kappa_{0 n}\right)+\left(2-\pi H_{1}\left(\kappa_{0 n}\right)\right) J_{0}\left(\kappa_{0 n}\right)}{J_{0}^{2}\left(\epsilon_{0 n}\right)},
\end{aligned}
$$

where $J_{0}$ and $J_{1}$ denote zero- and first-order Bessel functions of the first kind, $H_{0}$ and $H_{1}$ are zero- and first-order Struve functions and the numbers $\kappa_{0 n}$ are given by $\kappa_{0 n}=\epsilon_{0 n} R_{2} / R_{1}$, with $\epsilon_{0 n}$ being the $n$ roots of the first derivative of the zero-order Bessel function, see Appendix A.1 for more details. The solution appears to be rather intricate at first glance, but it allows for very fast calculations making it suitable for future integration into optimisation routines. Both the fitted and the analytical overpotential and corresponding relative errors are shown in figure 5 for different heights of the salt layer $H$ and electrode sizes $R_{2} / R_{1}$. The fitting functions lead to only very tiny errors, while the analytical formula deviates by up to $30 \%$ from the OpenFOAM simulations for very small 
$H$ and $R_{2}$. This was to be expected because iso-current boundary conditions had to be applied for the solution (12), whereas complementary iso-potential boundary conditions were used in the simulation. However, the introduced error is fairly low in a large parameter range such that the analytical solution still provides a good and fast estimate of the voltage loss.

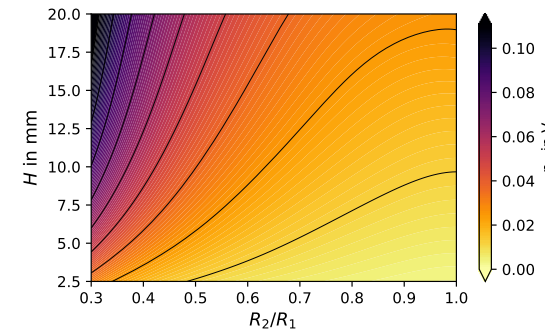

(a)

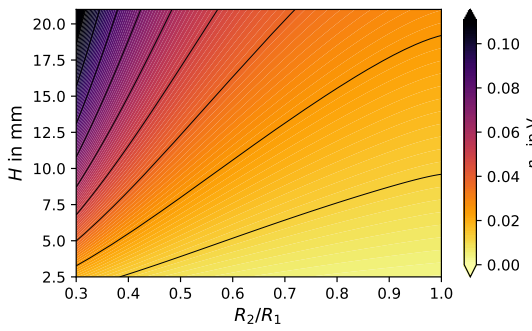

(c)

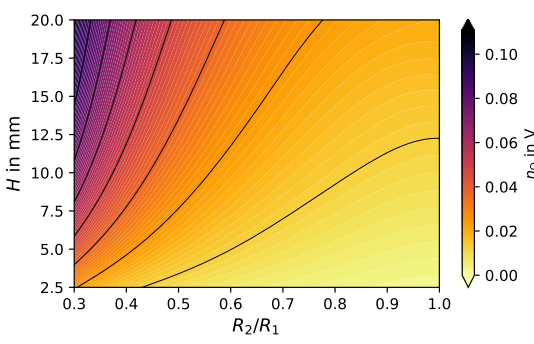

(e)

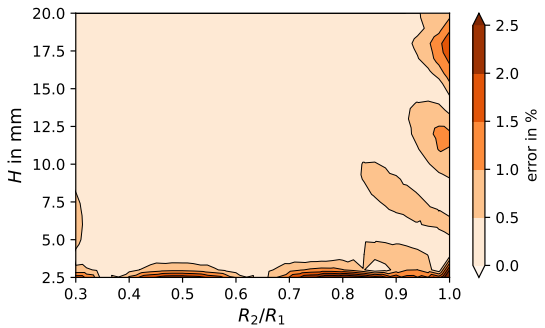

(b)

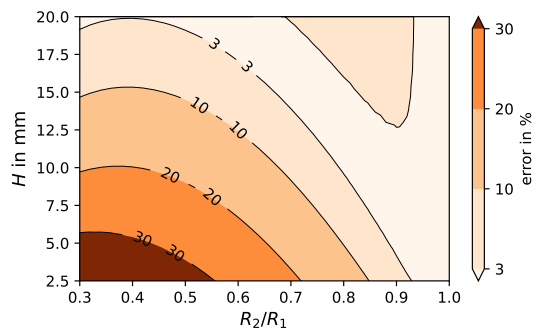

(d)

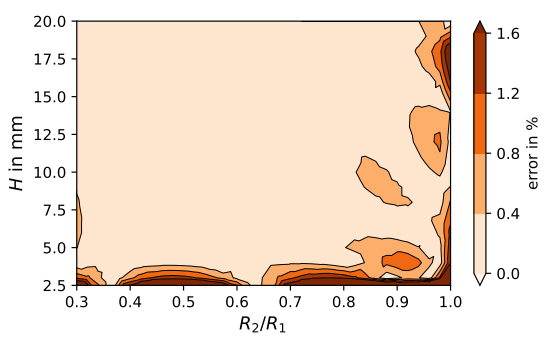

(f)

Figure 5: Fitted ohmic overpotential for a cylindrical cell (a) and corresponding error (b), analytically computed ohmic loss for the same cell (c) with error (d) and fitted ohmic overpotential for a square cell (e) with error (f). In the examples (a, c, e), $\sigma=1 \mathrm{~S} / \mathrm{cm}, I=1 \mathrm{~A}$, $R_{1}=5 \mathrm{~cm}$ and $L_{1}=10 \mathrm{~cm}$. 
Finally, it should be noted that the salt layer thickness will vary considerably during operation, if the negative electrode metal is contained in a fixed metalfoam. This volume change needs to be accounted for as explained in section 2.6 .

\subsection{Diffusion equation}

\subsubsection{General considerations}

The cell voltage of the LMB depends on the Li molar fraction at the positive electrode-electrolyte interface. In order to obtain the latter, a diffusion equation for the Li-concentration in Bi needs to be solved. According to Newhouse [38], the finite geometry of the positive electrode, its volume change and the concentration dependent diffusion coefficient need to be taken into account.

The general diffusion equation reads [50]

$$
\frac{\partial c}{\partial t}=\nabla \cdot D \nabla c
$$

with $D$ denoting the diffusion coefficient, $t$ the time and $c$ the concentration. It can either be solved for the molar $\left(\mathrm{mol} / \mathrm{m}^{3}\right)$ or for the mass concentration $\left(\mathrm{kg} / \mathrm{m}^{3}\right)$. However, when including convection in the cell voltage model, only the mass concentration is applicable any more, because the Navier-Stokes equations are written for a mass-averaged velocity. The density is strongly dependent on the concentration of $\mathrm{Li}$ in $\mathrm{Bi}$. Therefore, the molar and mass averaged velocities are not equal - for a detailed explanation, see Levicky [51]. Finally, it is not admissible to solve directly for mass or molar fraction. The transport equation of the latter is derived by dividing Fick's law (equation 13) by the density. As the density changes continuously, when alloying $\mathrm{Li}$ into $\mathrm{Bi}$, this operation is not permitted [52].

After solving the diffusion equation, the equilibrium cell potential can be obtained by converting the concentration to molar fraction as explained in section 2.5 . 


\subsubsection{Analytical solutions}

The diffusion equation (13) can be solved analytically for a semi-infinite geometry with the concentration gradient $q$ at the electrolyte interface as [38, p.83]

$$
q=\nabla c \cdot \boldsymbol{n}=\frac{j}{\nu_{e} \mathrm{~F} D},
$$

where $c$ denotes the molar concentration, $\boldsymbol{n}$ the normal vector and $\nu_{e}$ the number of exchanged electrons. Using the approach of Carslaw [53, p. 75] with $f=F_{0}=$ $D q=j /\left(\nu_{e} \mathrm{~F}\right), K=D, \kappa=D$, we obtain the concentration at the interface as

$$
c=c_{0}+2 q\left(\frac{D t}{\pi}\right)^{1 / 2}
$$

with the initial concentration $c_{0}$. The concentration inside the layer reads [53]

$$
c=c_{0}+2 q\left(\left(\frac{D t}{\pi}\right)^{1 / 2} \exp \left(-z^{2} /(4 D t)\right)-\frac{z}{2} \operatorname{erfc} \frac{z}{2 \sqrt{D t}}\right),
$$

with $z$ denoting the vertical coordinate. By defining the integral of the error function ierfc as

$$
\operatorname{ierfc}(z)=\frac{1}{\sqrt{\pi}} e^{-z^{2}}-z \cdot \operatorname{erfc}(z)
$$

we obtain

$$
c=c_{0}+2 q \sqrt{D t}\left(\operatorname{ierfc} \frac{z}{2 \sqrt{D t}}\right),
$$

and replacing $z$ by $H-z$ with $H$ denoting the layer thickness finally leads to

$$
c=c_{0}+\frac{2 j \sqrt{D t}}{\nu_{e} \mathrm{~F} D}\left(\operatorname{ierfc} \frac{H-z}{2 \sqrt{D t}}\right) .
$$

Here, the coordinate $z$ runs from the interface downwards. This approach has already been used for LMBs by Personnettaz et al. [24]. Of course, the simplification of a semi-infinite layer is only valid for thick layers or short charge/discharge times.

Alternatively, the diffusion equation can be solved analytically for a finite layer with the same boundary condition at the electrolyte interface as above, and $\nabla c \cdot \boldsymbol{n}=0$ at the bottom [38]. Using the original solution for heat transfer 
[53, p. 112] and setting $\rho c_{p}=1, K=D, \kappa=K / c_{p}=D$ and $F_{0}=D q=\frac{j}{\nu_{e} \mathrm{~F}}$ we obtain [54, p. 61][39]

$c=c_{0}+\frac{j H}{\nu_{e} \mathrm{~F} D}\left(\frac{D t}{H^{2}}+\frac{3 z^{2}-H^{2}}{6 H^{2}}-\frac{2}{\pi^{2}} \sum_{i=1}^{\infty} \frac{(-1)^{i}}{i^{2}} \exp \left(-D i^{2} \pi^{2} t / H^{2}\right) \cos \frac{i \pi z}{H}\right)$.

This approach has already been used for LMBs by Newhouse [38]; for alternative formulations of the same equation, see $[38,53]$.

\subsubsection{Numerical solution}

The analytical solutions of the diffusion equation are fast to compute, but neither account for the concentration dependent diffusion coefficient nor for volume change. Therefore, equation (13) is discretised using finite differences and finite volumes following Ferziger and Perić [55] as explained in detail in Appendix B.1 and Appendix B.2. The resulting equation system is solved in Python [56].

Volume change is accounted for by adjusting the cell volume or distance between the discretisation points in each time step. For this purpose, the initial masses in each control volume (CV) or at each point are computed, and then updated in every iteration. After computing the density using equation (35), the volume of each CV is obtained. The latter is used to compute a correction factor to increase either the size of the CV (finite volumes) or the distance between the points (finite differences). As the amount of moles of Li needs to stay constant during this operation, the concentration needs to be divided by the same factor, when increasing the volume.

\subsection{Conversion between concentration and molar fraction}

The equilibrium cell potential is given as function of the molar fraction (section 2.2). However, it is not possible to solve for the molar fraction directly - instead, the equations need to be written for molar or mass concentration (section 2.4). Hence, a conversion between concentration and fraction is required in both directions: from fraction to concentration to obtain the initial condition 
for the diffusion equation (13) and from concentration to molar fraction to obtain the cell voltage by equation (2).

The molar concentration of Li can be described as

$$
c=\frac{n_{\mathrm{Li}}}{V}=\frac{x \cdot n}{V}
$$

with $n_{\mathrm{Li}}$ denoting the amount of $\mathrm{Li}$ in mol, $n$ denoting the total amount of $\mathrm{Li}$ and Bi and $V$ the volume. This gives with $n=m / M, V=m / \rho$ and $M=\sum_{i} x_{i} M_{i}$

$$
\begin{aligned}
& c=\frac{\rho(x) x}{x M_{\mathrm{Li}}+(1-x) M_{\mathrm{Bi}}}, \\
& x=\frac{c M_{\mathrm{Bi}}}{\rho(c)-c M_{\mathrm{Li}}+c M_{\mathrm{Bi}}} .
\end{aligned}
$$

As the density is usually only given as function of the molar fraction $\rho(x)$ (section 3.2 ), the second formula cannot simply be used. Converting concentration to molar fraction is possible using one of the following simplifications:

1. Using a linear density law allows for an arbitrary conversion between concentration and fraction without further simplifications. As the linear approximation holds only near a working point, it should be used for short charge/discharge times only. A good domain of application are complex three-dimensional simulations [41] together with the Oberbeck-Boussinesq approximation [57, 58].

2. The concentration of Bi might be assumed to be constant during the time of simulation. Then, the mole fraction is given as $x=c_{\mathrm{Li}} /\left(c_{\mathrm{Li}}+c_{\mathrm{Bi}}\right)$. Again, this simplification should be limited to short discharge times.

3. The density might be fitted twice - once for concentration and once for mole fraction, as explained in section 3.2. Even though both fits will not be perfectly equivalent, this allows an easy conversion between $c$ and $x$ and back using formulae 22 and 23.

4. Assuming the density to be constant is a very strong simplification, limited to very short operation times.

5. The equilibrium cell potential might be directly fitted as function of the concentration. Although this approach seems easy, as it eliminates the 
molar fraction from all equations, it has one drawback: the phase diagram needs to be converted from $x$ to $c$. In this step, it gets an additional dimension, because $c$ depends on temperature, while $x$ does not.

Within this work, we will use simplification (3) as it is the most accurate one for long discharge times.

\subsection{Volume change}

When the cell is discharged, and $\mathrm{Li}$ alloys into $\mathrm{Bi}$, the positive electrode thickness will increase. This volume change needs to be accounted for, when solving the diffusion equation [38]. In most of the LMBs built in the past, the Lithium was contained in a metal-foam current collector, mounted at a fixed position. If in these cells the positive electrode layer changes its thickness, the electrolyte layer height will change at the same time. Considering the high ohmic resistance of the molten salt, the volume change of the electrolyte might be a very important effect.

The change of height of the positive electrode layer during operation can be estimated as

$$
\Delta H=\frac{x \frac{n_{\mathrm{Bi}}}{1-x} M_{\mathrm{Li}}+m_{\mathrm{Bi}}}{S \rho(x)}-\frac{x_{0} \frac{n_{\mathrm{Bi}}}{1-x_{0}} M_{\mathrm{Li}}+m_{\mathrm{Bi}}}{S \rho\left(x_{0}\right)}
$$

with $x_{0}$ denoting the initial Li molar fraction, $m$ the mass and $S$ the surface area. Figure 6 gives an illustrative example for the large Li-Bi cell experiment, described in section 4.3. There, the positive electrode layer changes between charged and discharged state between a thickness of 2.7 and $6.5 \mathrm{~mm}$, i.e. roughly by a factor of two. The volume change is considerable - and needs to be accounted for when solving the diffusion equation, but also when computing the ohmic overpotential.

An elegant way to account for volume change in LMBs when solving the diffusion equation has been introduced by Newhouse [38]. She solved the diffusion equation in a solvent-fixed reference frame, which means that no net flow of $\mathrm{Bi}$ (the solvent) occurs over the single control volumes [59-61]. This approach involves introducing a new spatial unit $\xi$, which describes the distance between 


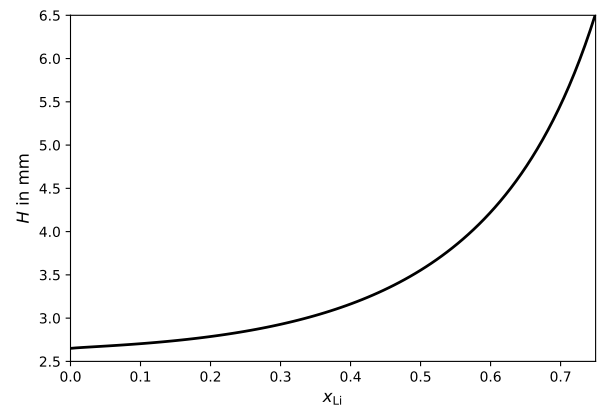

Figure 6: Thickness of the positive electrode layer as function of the Li molar fraction in $\mathrm{Bi}$ for the experiment described in section 4.3 .

two solvent atoms, and to convert the diffusion coefficient to this reference frame. After solving the modified diffusion equation, and obtaining the Li-flux relative to the Bi-atoms, the solvent-fixed concentration needs to be reconverted to the "true" concentration. This approach is based on the original article by Hartley and Crank [62] (available also in [54]), which is very well explained by Gekas and Lamberg [63] and has been used for other applications, as well [64, 65]. Apart from the difficult derivation, the biggest drawback of this approach is the assumption of constant partial volumes - i.e. the assumption that the alloy density can be described as that of an ideal solution (equation 30).

An alternative approach is to compute every single cell volume in each time step, when solving the diffusion equation. Then, the size of the control volume can be updated in real-time. When solving the diffusion equation in $1 \mathrm{D}$, as explained in Appendix B.1 and Appendix B.2, the distances between two nodes need to be scaled, respectively.

\section{Material properties}

\subsection{Conductivity}

The electrical conductivity of the molten salt is required to compute the ohmic losses. In the past, mostly mixtures of $\operatorname{LiCl}-\operatorname{LiF}[2,11,12,17,18]$ and LiCl-LiF-LiI [21-23] have been used for Li-Bi cells. $\mathrm{LiCl}-\mathrm{KCl}$ was employed 
as well $[11,13-15]$, although it is known that $\mathrm{Li}$ reduces $\mathrm{KCl}$ at temperatures above $500{ }^{\circ} \mathrm{C}[17,66]$. Table 3 gives an overview on the melting temperature and conductivity of the salts.

Table 3: Electric conductivity $\sigma$ and melting temperature $\vartheta_{m}$ of the molten salts.

\begin{tabular}{|c|c|c|c|c|}
\hline salt & composition in mol\% & $\vartheta_{m}$ in ${ }^{\circ} \mathrm{C}$ & $\sigma$ in $\mathrm{S} / \mathrm{cm}$ & source \\
\hline \multirow[t]{3}{*}{ LiCl-LiF } & $70: 30$ & 501 & & {$[2]$} \\
\hline & & & 6.78 at $927^{\circ} \mathrm{C}$ & {$[67]$} \\
\hline & various & & & {$[68]$} \\
\hline \multirow[t]{5}{*}{ LiCl-LiF-LiI } & eutectic & 340.9 & 3 at $475^{\circ} \mathrm{C}$ & {$[21]$} \\
\hline & eutectic & 340.9 & 2.3 at $475^{\circ} \mathrm{C}$ & {$[69$, p. 97$]$} \\
\hline & $29.1: 11.7: 59.2$ & 340.9 & 2.3 at $375^{\circ} \mathrm{C}$ & {$[21]$} \\
\hline & $29.1: 11.7: 59.2$ & 341 & 2.3 at $375^{\circ} \mathrm{C}$ & {$[22$, p. 167$]$} \\
\hline & $29.1: 11.7: 59.1$ & 341 & $8.895 \exp (-872.6 / T)$ & {$[70]$} \\
\hline \multirow[t]{10}{*}{$\mathrm{LiCl}-\mathrm{KCl}$} & & 354 & 1.83 at $500^{\circ} \mathrm{C}$ & {$[71]$} \\
\hline & $40.45: 59.55$ & & $13.21 \exp (-13995.71415 / R T)$ & {$[72$, p. 205$]$} \\
\hline & $41: 59$ & 353 & 1.7 at $476^{\circ} \mathrm{C}$ & {$[1]$} \\
\hline & $58.8: 41.2$ & 353 & 1.57 at $450^{\circ} \mathrm{C}$ & {$[22$, p. 167$]$} \\
\hline & $58.8: 42.2$ & & $18.7876 \exp (-1800.6 / T)$ & [70] \\
\hline & $58.8: 41.2$ & & $23.021 \exp (-16204.90311 / R T)$ & {$[72$, p. 205] } \\
\hline & $70.36: 29.64$ & $-11.0108+$ & $2.7461 \cdot 10^{-2} T-13.2471 \cdot 10^{-6} T^{2}$ & {$[73$, p. 1045$]$} \\
\hline & $81.77: 18.23$ & & $13.886 \exp (-9982.35421 / R T)$ & {$[72$, p. 205] } \\
\hline & various & & & {$[73$, p. 1045$]$} \\
\hline & various & & & {$[74]$} \\
\hline
\end{tabular}

\subsection{Density}

The densities of molten $\mathrm{Li}$ and $\mathrm{Bi}$ are given in $\mathrm{kg} / \mathrm{m}^{3}$ as $[75, \mathrm{p} .14-10]$

$$
\begin{aligned}
& \rho_{\mathrm{Li}}=518-0.1(T-453.5) \\
& \rho_{\mathrm{Bi}}=10050-1.18(T-544)
\end{aligned}
$$

with $T$ denoting the temperature in K. Densities of binary alloys are sometimes estimated based on Vegard's law [76]. The latter predicts a linear relation of the mean lattice distance in a solid solution, if two different components are mixed. Applied to fluid mixtures, it is assumed that the volume $V$ can be computed as a linear weight of the amounts of the substances $n_{i}$ and the third roots of their molar volumes $v_{i}$ as [77]

$$
V=\sum\left(n_{i} \sqrt[3]{v_{i}}\right)^{3}
$$


which leads for a binary alloy of component 1 and 2 to [77]

$$
\rho=\frac{x_{1} M_{1}+\left(1-x_{1}\right) M_{2}}{\left(x_{1} \sqrt[3]{M_{1} / \rho_{1}}+\left(1-x_{1}\right) \sqrt[3]{M_{2} / \rho_{2}}\right)^{3}} .
$$

Alternatively, the volume of an ideal solution can be described as the sum of its components as

$$
V=\sum n_{i} v_{i}
$$

which leads to the very similar equation [78]

$$
\rho=\frac{x_{1} M_{1}+\left(1-x_{1}\right) M_{2}}{\left(x_{1} M_{1} / \rho_{1}+\left(1-x_{1}\right) M_{2} / \rho_{2}\right)} .
$$

Both density laws are not well suited for $\mathrm{Li}-\mathrm{Bi}$, as can be seen in figure 7 . The deviation from Vegard's law perhaps can be explained by electronic structure. While $\mathrm{Li}$ is strongly electropositive $(\chi=0.98), \mathrm{Bi}$ is considerably more electronegative $(\chi=1.9)$. This difference might cause a deviation from ideality for the liquid solution - similar as the Hume-Rothery Rules predict for solid state solutions a deviation from ideality for large electronegativity differences.

Only few density values for the Li-Bi alloy are available in the literature [79-83]. These data are used to fit the density as

$$
\rho=\frac{x M_{\mathrm{Li}}+(1-x) M_{\mathrm{Bi}}}{\left(x^{0.94} M_{\mathrm{Li}} / \rho_{\mathrm{Li}}+(1-x)^{1.64} M_{\mathrm{Bi}} / \rho_{\mathrm{Bi}}\right)} .
$$

As illustrated in figure 7, this fitted function is describing the Li-Bi density best, and is therefore used in the following.

In order to allow an easy conversion between concentrations and molar fractions, the density is fitted as function of the concentration, as well. For this purpose, the molar fractions belonging to the measured density values are first converted to the Li molar concentrations as

$$
c=\frac{\rho x}{x M_{\mathrm{Li}}+(1-x) M_{\mathrm{Bi}}}
$$

with $\rho$ denoting the mixture density. The resulting fit function fulfils the boundary conditions

$$
\begin{array}{r}
\rho(c=0)=\rho_{\mathrm{Bi}} \\
\rho\left(c=c_{\infty}\right)=\rho_{\mathrm{Li}}
\end{array}
$$


and reads

$$
\rho=\frac{\alpha \cdot c^{\gamma}+\beta \cdot\left(c_{\infty}-c\right)^{\delta}}{\alpha \cdot \frac{c_{\infty}^{\gamma}}{\rho_{\mathrm{Li}}}\left(\frac{c}{c_{\infty}}\right)^{\varepsilon}+\beta \cdot \frac{c_{\infty}^{\delta}}{\rho_{\mathrm{Bi}}}\left(\frac{c_{\infty}-c}{c_{\infty}}\right)^{\varphi}}
$$

with the concentration of pure $\mathrm{Li}$ defined as

$$
c_{\infty}=\frac{\rho(x=1)}{M_{\mathrm{Li}}}=\frac{\rho_{\mathrm{Li}}}{M_{\mathrm{Li}}}
$$

and

$$
\varepsilon=1.45, \varphi=0.67, \alpha=8.1 \cdot 10^{-9}, \beta=37, \gamma=2.37 \text { and } \delta=0.7 \text {. }
$$

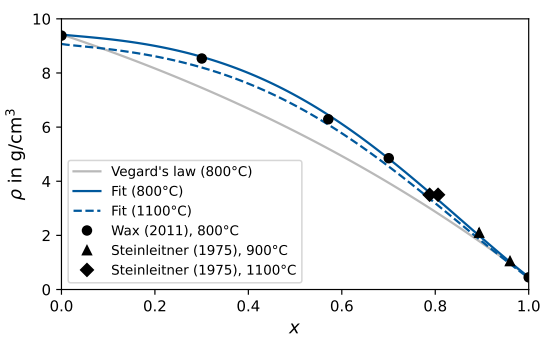

(a)

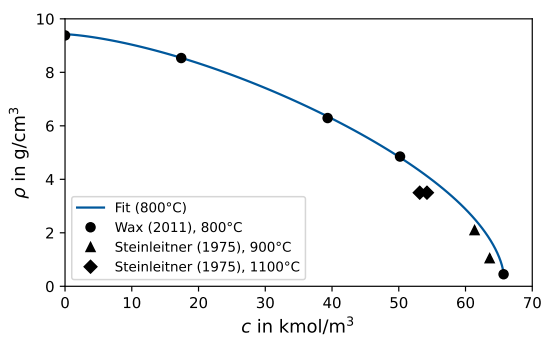

(b)

Figure 7: Density of Li-Bi depending on the Li molar fraction (a) and Li concentration (b).

\subsection{Diffusion coefficient}

Diffusion coefficients of $\mathrm{Li}$ in $\mathrm{Bi}$ have been measured by Temnogorova et al., Weppner et al., van Norman and Newhouse, as shown in table 4 and figure 8. Due to the available concentration dependence, we use the formula of Newhouse.

\subsection{Thermodynamic properties}

The thermodynamics of the Li-Bi system have been studied several times

- table 5 gives an overview on literature sources for the activity $a_{\mathrm{Li}(\mathrm{Bi})}$, the Gibbs free energy $G$, the equilibrium cell potential $\left(E_{\text {eq }}\right)$, the enthalpy $H$ and the entropy $S$. 
Table 4: Diffusivity of Li in Bi.

\begin{tabular}{rrl}
\hline \multicolumn{1}{c}{$\vartheta$ in $\mathrm{cm}^{2} / \mathrm{s}$} & ${ }^{\circ} \mathrm{C}$ & \multicolumn{1}{c}{ source } \\
\hline $2.2 \cdot 10^{-5}$ & 450 & {$[84]$} \\
$1.56 \pm 0.15 \cdot 10^{-5}$ & 500 & {$[15]$} \\
$3.25 \pm 0.53 \cdot 10^{-5}$ & 550 & {$[15]$} \\
$3.27 \pm 0.3 \cdot 10^{-5}$ & 550 & {$[15]$} \\
$\operatorname{various}\left(\mathrm{Li}_{3} \mathrm{Bi}\right)$ & $360-600$ & {$[3]$} \\
$\exp \left(\frac{-4.081 c-0.01315}{c^{2}+0.3742 c+0.001572}\right)$ & 450 & {$[38, \mathrm{p} .174]$} \\
\hline
\end{tabular}

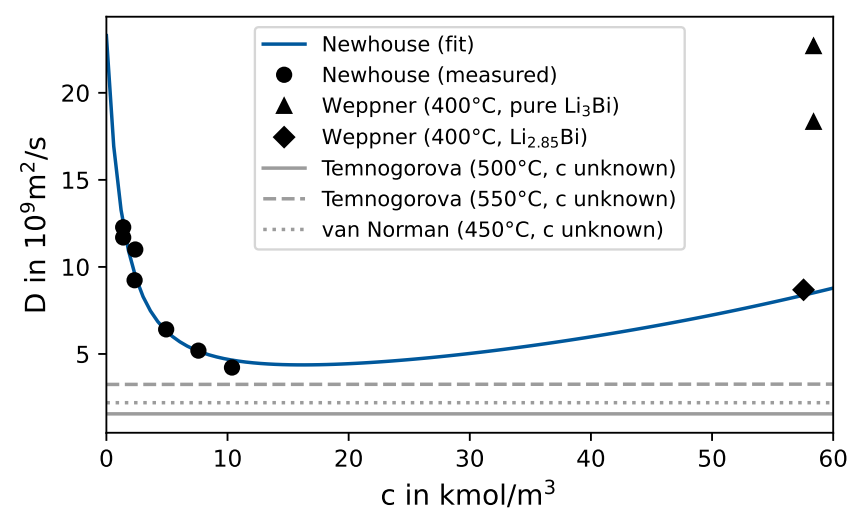

Figure 8: Concentration dependent diffusivity according to various authors and fit by Newhouse [38]; $x$ has been converted to $c$ using equations (31) and (32).

\section{Results}

\subsection{Small Li-Bi cell}

The first use case for the developed model is illustrated in figure 9 - a small $\mathrm{Li}-\mathrm{Bi}$ cell with a diameter of approximately $3 \mathrm{~cm}$. The Li-metal is contained in spirally rolled $\mathrm{Ni}$-sheet serving as current collector and separated from the positive electrode by an effectively 3-4 mm thick eutectic LiCl-LiF-LiI electrolyte.

The metals (Li: Alfa Aesar, 99.9\%; Bi: Alfa Aesar, 99.998\%) were first cleaned mechanically (oil removal and skin cut off for $\mathrm{Li}$ ), before melting them and skimming floating pollutants. Additionally, a small amount of salt was 
Table 5: Sources for thermodynamic properties of the Li-Bi system: activity $\left(a_{\mathrm{Li}(\mathrm{Bi})}\right)$, Gibbs free energy $(G)$, equilibrium cell potential $\left(E_{\text {eq }}\right)$, entropy of mixing $(S)$ and enthalpy of mixing $(H)$.

\begin{tabular}{|c|c|c|c|c|c|c|}
\hline phase diagram & ${ }^{a} \mathrm{Li(Bi)}$ & G & $E_{\mathrm{eq}}$ & $s$ & $H$ & literature \\
\hline \multirow[t]{4}{*}{ - } & - & - & & - & - & [85] \\
\hline & & & - & & & {$[5$, p. 152$]$} \\
\hline & & - & & & & {$[12$, p. 118$]$} \\
\hline & & & - & & & {$[14$, p. 216$]$} \\
\hline \multirow[t]{2}{*}{$\bullet$} & & & & & & [2] \\
\hline & & & - & & & {$[18$, p. 226$]$} \\
\hline - & & - & - & & & [17] \\
\hline \multirow[t]{2}{*}{ - } & & - & - & - & - & [20] \\
\hline & & & - & & & [86] \\
\hline \multirow[t]{6}{*}{ - } & - & - & & - & - & [87] \\
\hline & - & - & - & - & - & [19] \\
\hline & & & - & & & {$[11$, p. $109 f]$} \\
\hline & & & - & & & {$[88$, p. $143 \mathrm{f}]$} \\
\hline & & & - & & & {$[38$, p. $110 \mathrm{f}]$} \\
\hline & & & - & & & [44] \\
\hline \multirow[t]{3}{*}{ • } & - & & & & - & [42] \\
\hline & - & & & & & [84] \\
\hline & - & & - & & & [89] \\
\hline
\end{tabular}

added to bind remaining impurities. After freezing the contaminated salt, the clean metal was poured into a second crucible. To prepare the electrolyte, $\mathrm{LiCl}$ (Alfa Aesar, 99.995\%) and LiF (Beantown, 99.99\%) were mixed and allowed to rest for several hours at $550^{\circ} \mathrm{C}$. LiI (Beantown, 99.95\%) was added thereafter, and the complete mixture filtered though a glass frit.

The tantalum crucible was filled with $0.1 \mathrm{~mol} \mathrm{Bi}$ and $18.5 \mathrm{~g}$ electrolyte. Finally, molten Li was soaked into the negative electrode current collectors (Ni alloy 200). The cell was operated on a ceramic heating plate (BACH Resistor Ceramics $)$ in a glove box filled with argon gas $\left(\mathrm{H}_{2} \mathrm{O}<0.1 \mathrm{ppm}, \mathrm{O}_{2}<0.1 \mathrm{ppm}\right)$ at a heating plate temperature of $460^{\circ} \mathrm{C}$ [24].

The modelling work starts with the initial condition: the known mass of $\mathrm{Bi}$, and the measured equilibrium cell potential lead to the initial Li-concentration in $\mathrm{Bi}$. Then, the amount of $\mathrm{Li}$, which leaves the positive electrode during charge, is calculated. Considering the strong solutal convection during charging, perfect mixing is assumed [24]. The ohmic loss for charging is obtained for each timestep using equation (A.11) and taking the change of the electrolyte layer height into account; as the latter changes with time, it is derived from the known 

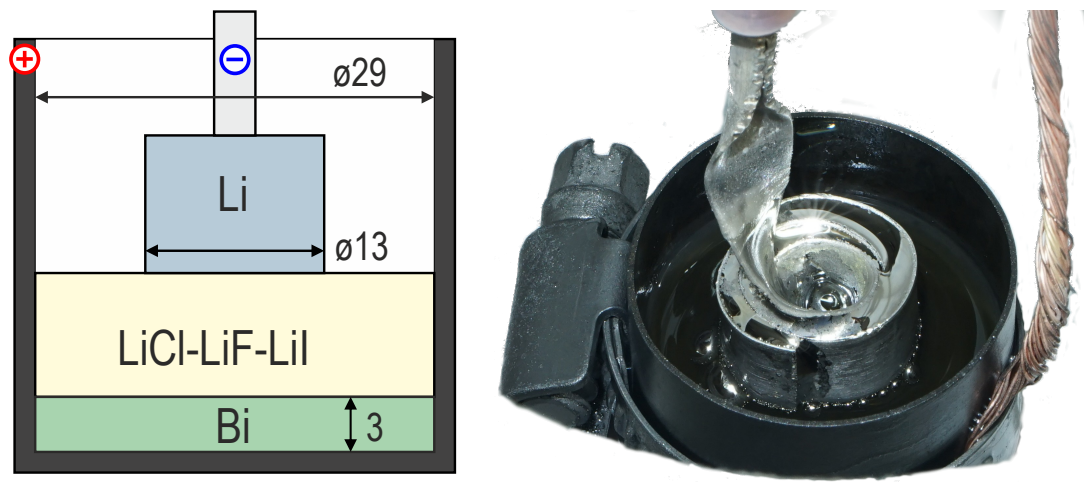

Figure 9: Setup and dimensions (in $\mathrm{mm}$ ) of the small Li-Bi laboratory cell (not to scale). The thicknesses of positive electrode and electrolyte are given for the start of the charge phase (figure 10).

conductivity and geometry.

Switching to discharging, the current direction is reversed and Li transferred back to the positive electrode. For comparison, the diffusion equation is solved once by the analytical solutions for a finite and semi-infinite layer and once numerically. The latter accounts for volume change of positive electrode and electrolyte as well as the variable diffusivity, while the analytical solutions neglect volume change at all and use a constant diffusion coefficient of $4 \cdot 10^{-5} \mathrm{~cm}^{2} / \mathrm{s}$.

Comparing the measured and modelled curves, it becomes apparent that an approximate reproduction of experimental curves is easy. Already Personnettaz et al. [24] reproduced the same experiment using an estimated diffusion coefficient of $7 \cdot 10^{-5} \mathrm{~cm}^{2} / \mathrm{s}$ and a different formulation for the mixture density. Obtaining a perfect match is, however, challenging. For example, the small deviation of the equilibrium cell potential before charge/discharge is probably caused by the fit function (equation 2). As no measured electromotive force values were available for $460^{\circ} \mathrm{C}$, the fit had to be slightly extrapolated. The small mismatch of the cell potential during charge is surely related to the ohmic loss. While the positive electrode layer changes its height by $5 \%$ during cycling, it is not easy to predict the exact shape of the negative electrode. The Li might be 


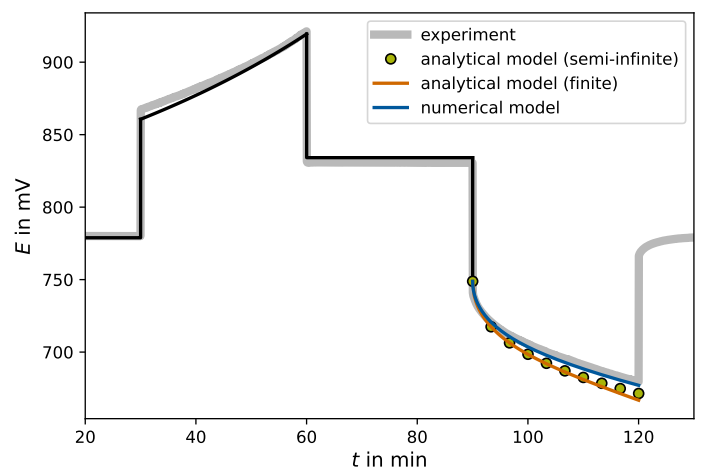

Figure 10: Measured charge-discharge curve at $1 \mathrm{~A}$ and modelled curves using the analytical solution for a finite and semi-infinite layer and the numerical solution with variable diffusivity and volume change.

soaked fully into the Ni-sheet or form a large droplet below it. The shape of this droplet might vary due to the Lorentz forces at charge/discharge and also due to the transfer of Li-metal [90]. Finally, the slight deviation of the discharge curves might be related to the three-dimensionality of the diffusion problem. While the model assumes only downward diffusion, Li will in reality also diffuse sidewards in the positive electrode - which then increases the cell voltage. Moreover, any very small flow effects, caused, e.g. by Marangoni convection or electro-vortex flow, might lead to a higher cell potential, too. Anyway, the numerical solution is extremely close to the measured cell potential.

\subsection{Large Li-Bi cell}

Highlighting the broad applicability of the developed model, a second, larger Li-Bi cell will be studied. Now, the cell diameter is $9 \mathrm{~cm}$, with the negative electrode metal being contained in a $\mathrm{Ni}$ foam as shown in figure 11.

Metals and salts were cleaned as for the small cell (section 4.1). The battery was set up by pouring $1 \mathrm{~mol}$ Bi into the tantalum vessel and adding $80.28 \mathrm{~g}$ eutectic LiCl-LiF-LiI electrolyte. The negative current collector (Ni foam, Recemat BV) was prepared by heating $1.5 \mathrm{~mol} \mathrm{Li}$ in a stainless steel vessel to $450{ }^{\circ} \mathrm{C}$ and letting the foam rest for $2 \mathrm{~h}$ in the bath. Finally, the cell was operated such 

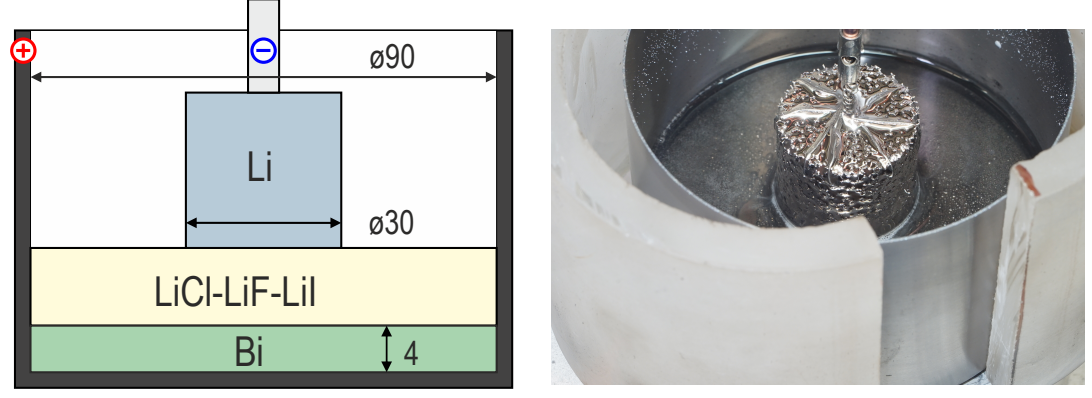

Figure 11: Setup and dimensions (in $\mathrm{mm}$ ) of the large Li-Bi cell (not to scale). The layer thicknesses are given for the start of discharge in figure 12 .

that the heating plate obtained a temperature of $500^{\circ} \mathrm{C}$, while the salt reached only $420^{\circ} \mathrm{C}$.

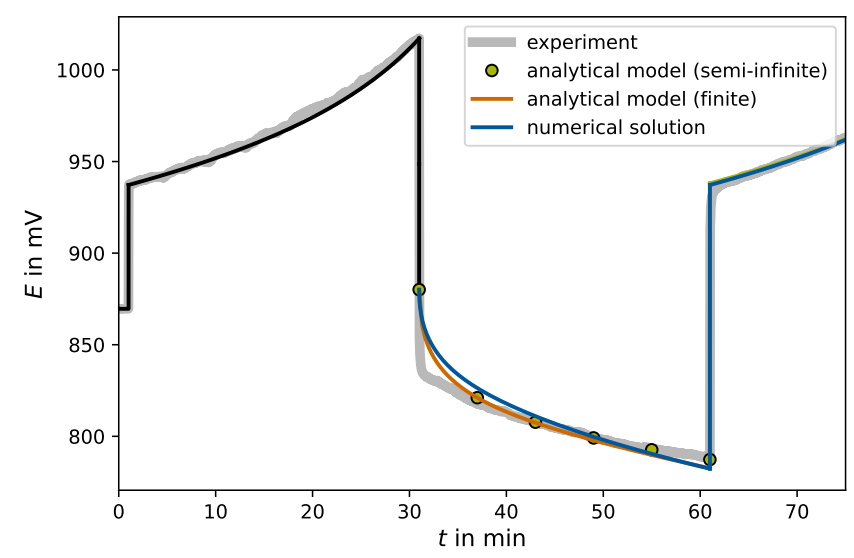

Figure 12: Experimental and numerical charge-discharge curve for the large Li-Bi cell at $5 \mathrm{~A}$.

The charge/discharge curve is modelled exactly like for the previous experiment: the initial values are obtained from the measured electromotive force and the positive electrode is assumed to be well mixed at charge. Volume change is accounted for during charge, but during discharge only when solving the diffusion equation numerically. As the cell is operated with a Li-concentration of 1 to $5 \mathrm{kmol} / \mathrm{m}^{3}$, a diffusion coefficient of $7 \cdot 10^{-5} \mathrm{~cm}^{2} / \mathrm{s}$ is assumed when using the analytical solutions of the diffusion equation. 
The model reproduces the experimental data very well - with a certain deviation during the discharge phase. Compared to the small Li-Bi cell experiment described in section 4.1 the charge phase is reproduced better. The reason is most likely that the negative electrode shape is now defined much better, as the $\mathrm{Li}$ is contained in a metal foam instead of a rolled $\mathrm{Ni}$-sheet. The slight deviation during cell discharge can most probably be attributed to the threedimensionality of the problem. As the positive electrode diameter is three times larger than the negative electrode, substantial lateral diffusion will occur, which surely influences the cell voltage. Nevertheless, the experimental curve is reproduced reasonably well.

\subsection{Li-Bi cell by Ning et al.}

The last test case is a large Li-Bi cell built at Massachusetts Institute of Technology and published by Ning et al. [2]. The setup is shown in figure 13: the cell is $15 \mathrm{~cm}$ in diameter, containing $455 \mathrm{~g}$ of $\mathrm{Bi}$, which results in a $2.7 \mathrm{~mm}$ thick positive electrode layer. The Li-negative electrode is soaked into a $\mathrm{Ni}$ foam, and is assumed to be $10 \mathrm{~cm}$ in diameter. The cell operates at $550^{\circ} \mathrm{C}$ using an eutectic LiCl-LiF (70:30 mol\%) electrolyte with an interelectrode distance of $10 \mathrm{~mm}$ in charged state. Having a capacity of $175 \mathrm{Ah}, 3 \mathrm{~h}$ and $20 \mathrm{~min}$ are theoretically needed to discharge the complete cell at a current density of $300 \mathrm{~mA} / \mathrm{cm}^{2}$.

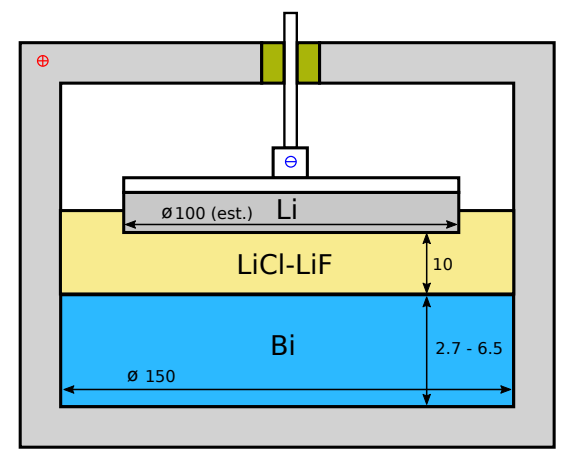

Figure 13: Setup and dimensions (in $\mathrm{mm}$ ) of the Li-Bi cell investigated by Ning et al. [2] (not to scale). 
Figure 14 illustrates the discharge curves of this cell using different models. The equilibrium cell potential (equation 5) - which would be obtained at very small current densities - clearly exhibits a long plateau in the two-phase area. When reaching a Li molar fraction of about 0.73 , there is a predicted extended intermetallic phase region [91]. In our model, the potential in this region decreases linearly to zero.

Discharging with a current density of $300 \mathrm{~mA} / \mathrm{cm}^{2}$, the numerical solution of the diffusion equation gives the most accurate result as it accounts for volume change as well as the concentration dependent diffusivity. As expected, the ohmic overpotential shifts the cell potential to lower values. Moreover, the usable cell capacity is reduced by roughly $30 \%$, as well. The reason is simply that due to the high current, a layer of saturated $\mathrm{Li}_{3} \mathrm{Bi}$ forms at the electrolytepositive electrode interface, which causes the cell potential to drop to $0 \mathrm{~V}$. The "missing" capacity is located just below of this intermetallic layer, where a stoichiometric composition of $\mathrm{Li}_{3} \mathrm{Bi}$ is not reached. The usable cell capacity depends therefore not only on the mass of the active materials and side reactions, but also on the discharge current.

Modelling the discharge curve with the analytical solution of the diffusion equation for a finite layer (equation 20) using an average diffusivity of $D=8 \cdot 10^{-5} \mathrm{~cm}^{2} / \mathrm{s}[41]$, the predicted capacity is only $50 \%$ of that found by the numerical solution. This considerable discrepancy is simply caused by the fact that volume changes are not considered. As the analytical solution of the diffusion equation neglects the fact that the positive electrode thickness changes approximately by a factor of two (see figure 6) between charge and discharge, it predicts a much lower capacity.

The analytical solution of the diffusion equation for a semi-infinite layer does the opposite: it predicts a much larger cell capacity than theoretically possible. As it ignores the lower boundary of the positive electrode, it assumes that much more Li can be alloyed into Bi than practically possible.

These examples highlight that the analytical solutions for the diffusion equation should not be used when considering full charge-discharge cycles as they 
induce considerable errors due to the negligence of volume-change effects.

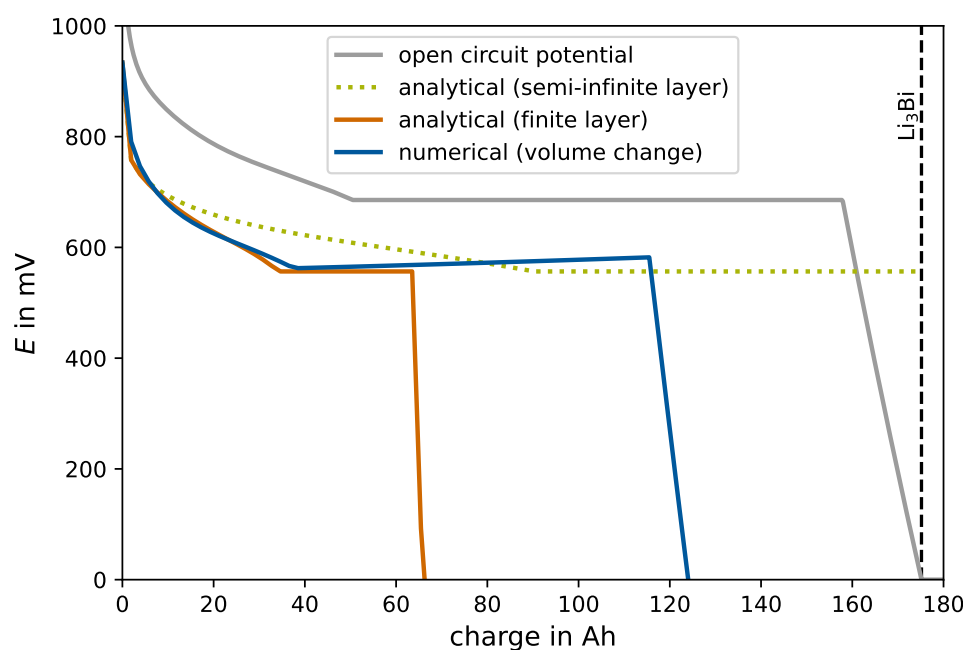

Figure 14: Discharge curves for $0.3 \mathrm{~A} / \mathrm{cm}^{2}$ using different numerical and analytical models.

\section{Application scenarios and limitations of the model}

\subsection{Use cases and application scenarios}

The developed model can easily be applied to other liquid metal batteries basically only the material properties need to be changed. Possible use cases or application scenarios span from basic to applied research and include, amongst others, the following:

- Preparation of experiments: battery cycling experiments can be presimulated, which helps to choose, e.g. an appropriate cycling time and cell current.

- Reference and validation: the model can be used as reference case or for validation purposes, e.g. when performing costly three-dimensional simulations of complete batteries.

- Cost assessment: the cell voltage is one of the most influential parameters of a battery cost model for LMBs [92]. The developed cell voltage model can make these estimations much more accurate. 
- Scale up and system modelling: the design of large battery stacks including hundreds of single cells for special use cases can largely be facilitated using optimisation algorithms, such as genetic algorithms. The developed cell voltage model could be integrated to provide the power, heat release, current and cell potential of the single cells. Especially, the simplicity and speed of our model would be very beneficial for such optimisation tasks.

- Battery management systems: the model can be used as the core of a battery management system. By only measuring the temperature and open circuit potential, it might provide for example the state of charge, estimate the charge or discharge time, the remaining capacity or the model might be used to predict the cell potential as function of time and battery current.

\subsection{Limitations and possible improvements}

Modelling the cell voltage of LMBs is a complex task, involving numerous simplifications and uncertainties. However, most of them are negligible and do not restrict the field of application of our model. In the opinion of the authors, the presented model and its portability to other geometries and cell chemistries is mainly limited by the following points:

1. Material properties: measured densities of typical LMB electrode couples are usually scarce. Moreover, diffusivities are not always available with their concentration dependence, and the measurement error may be considerable.

2. Complexity of intermetallic phases: the conductivity of the Li-Bi alloy changes by almost two orders of magnitude during alloying, reaching the same order of magnitude as for the molten salt, when forming the intermetallic phase [79, 93, 94]. The corresponding ohmic losses might be included in improved models. Likewise, the diffusivity of $\mathrm{Li}$ in Bi changes by a factor of up to 3 , when forming the intermetallic. This makes accurate predictions of mass transport challenging. 
3. Ohmic overpotential: the ohmic losses in the salt can usually not be approximated by a one-dimensional model. The fit equation, used here, might be replaced alternatively by solving a Laplace equation for the electric potential in $2 \mathrm{D}$ or $3 \mathrm{D}$.

4. One-dimensionality of mass transport: mass transport has been modelled as a one-dimensional effect. This simplification is often appropriate - as long as the negative electrode and positive electrode diameters are similar (see section 4.2 for an example, where this was not the case).

5. Simplification of flow effects: any type of flow can increase mass transfer [41]. This effect has been neglected. The positive electrode is simply be assumed to be perfectly mixed by solutal convection at charge [24], while mass transfer is assumed to be controlled by diffusion only at discharge. One example, where this does not work well, is shown in figure 15(a). When charging the large $\mathrm{Li}-\mathrm{Bi}$ cell described in section 4.2 with a very large current (here 20 A), a Li-depleted concentration layer will form in the positive electrode despite most of the volume is well mixed by solutal convection. The measured cell potential will rise therefore steeply, while the modelled potential is lower.

6. Memory effect: the cell potential is not only a function of the state of charge, but is history-dependent as well. Figure 15(b) shows one example: the measured cell potential of the first cycle is larger than the one of the two subsequent ones. At the beginning of cycling, the positive electrode was at rest and perfectly mixed. Therefore, solutal convection sets in immediately at charge, mixing the alloy well, and leading to a high cell voltage. After discharge, a stable density stratification formed. When now charging again, solutal convection takes longer to destroy the stable density stratification and to mix the positive electrode again - therefore, the potential of the second and third cycle is initially lower. Such "memory effects" can generally be accounted for using the developed model; however, care needs to be taken not to ignore them. 


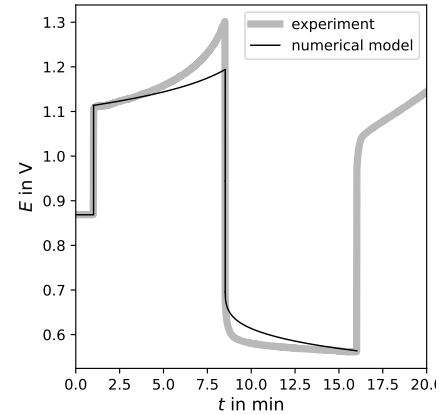

(a)

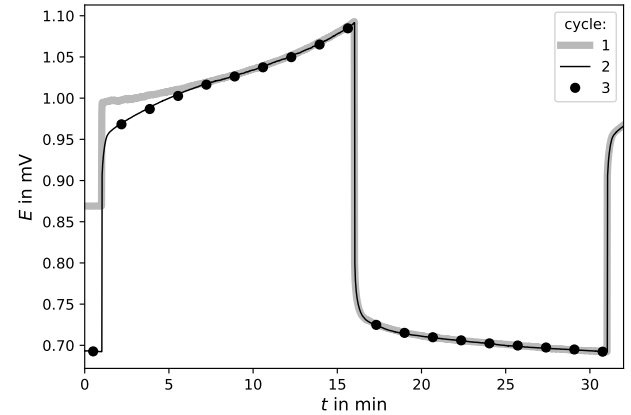

(b)

Figure 15: Experimental and modelled charge/discharge curve for the large Li-Bi cell presented in section 4.2 at $20 \mathrm{~A}$ (a) and overlay of the first three experimental cycles at $10 \mathrm{~A}$ (b).

\section{Summary}

The Lithium-Bismuth system is one of the best explored liquid metal batteries (LMBs). After discussing the peculiarities of this chemistry and summarising the previous experimental studies, we gave a short overview of the most relevant modelling work of LMBs. Further, we briefly described our motivation to develop a simple quasi-one-dimensional cell voltage model.

The equilibrium cell potential is obtained by a complex two-dimensional fit of experimental data as function of temperature and Li-molar fraction. While the very small activation losses have been neglected, different sub-models for the ohmic loss have been proposed. It was shown that the voltage drop in the salt can be solved analytically, but only under certain assumptions. As alternative, two fit functions for cylindrical and rectangular cells are provided, which describe the ohmic losses well.

Special care was taken to obtain the correct mass transfer overpotential. After discussing the possible formulations of the diffusion equation to obtain the Li-content in $\mathrm{Bi}$, different possibilities to convert molar and mass fraction to molar or mass concentration were proposed. Two analytical solutions for the diffusion equation were presented: one for a semi-infinite, and one for a finite positive electrode. Finally, a numerical scheme was implemented in the finite 
difference and finite volume method, which accounts for volume change of the positive electrode during operation.

The developed model was finally applied to three different Li||Bi cells. Although the results generally match well with the experimental data, the comparison revealed certain limitations of the model. Most importantly, the onedimensional model fails in describing three-dimensional mass transfer effects, which become important if the negative electrode and positive electrode diameter deviate strongly from each other. Moreover, the influence of flow effects on the cell voltage has been simplified to a large extend. The modelling of the three experiments further highlighted that for short-time cycling the analytical solutions of the diffusion equation are well suited. However, in order to describe the full discharge of an LMB, volume change is of highest importance, and needs to be included as well by solving the mass transport equation numerically.

\section{Software}

The raw data, python model and examples can be obtained from https: //doi.org/10.14278/rodare.1369.

\section{Acknowledgement}

This project has received funding from the European Union's Horizon 2020 research and innovation programme under grant agreement No 963599, from the Deutsche Forschungsgemeinschaft (DFG, German Research Foundation) by award number 338560565 and in frame of the Helmholtz - RSF Joint Research Group "Magnetohydrodynamic instabilities: Crucial relevance for large scale liquid metal batteries and the sun-climate connection", contract No. HRSF0044 and RSF-18-41-06201. We would like to thank A. Linke and J. Fuhrmann for fruitful discussions about the solution of the diffusion equation. 


\section{References}

[1] H. Kim, D. A. Boysen, J. M. Newhouse, B. L. Spatocco, B. Chung, P. J. Burke, D. J. Bradwell, K. Jiang, A. A. Tomaszowska, K. Wang, W. Wei, L. A. Ortiz, S. A. Barriga, S. M. Poizeau, D. R. Sadoway, Liquid Metal Batteries: Past, Present, and Future, Chem. Rev. 113 (3) (2013) 20752099. doi:10.1021/cr300205k.

[2] X. Ning, Satyajit Phadke, B. Chung, H. Yin, P. Burke, D. R. Sadoway, Self-healing Li-Bi liquid metal battery for grid-scale energy storage, J. Power Sources 275 (2015) 370-376. doi:10.1016/j.jpowsour.2014.10. 173.

[3] W. Weppner, R. A. Huggins, Electrochemical Investigation of the chemical diffusion, partial ionic conductivities, and other kinetic parameters in $\mathrm{Li}_{3} \mathrm{Sb}$ and $\mathrm{Li}_{3} \mathrm{Bi}$, J. Solid State Chem. 22 (1977) 297-308.

[4] M. S. Foster, C. E. Crouthamel, D. M. Gruen, R. L. McBeth, First Observation of a Solution of $\mathrm{Li}_{3} \mathrm{Bi}$, An Intermetallic in Molten Lithium Chloride and Lithium Chloride-Lithium Fluoride, J. Phys. Chem. 68 (4) (1964) 980-981.

[5] R. C. Vogel, M. Levenson, V. H. Munnecke, Chemical engineering division research highlights, Tech. Rep. ANL-6875, Argonne National Laboratory (1964).

[6] R. C. Vogel, M. Levenson, F. R. Masten, Chemical engineering division semiannual report, Tech. Rep. ANL-6900, Argonne National Laboratory (1964).

[7] T. Weier, A. Bund, W. El-Mofid, G. M. Horstmann, C.-C. Lalau, S. Landgraf, M. Nimtz, M. Starace, F. Stefani, N. Weber, Liquid metal batteries - materials selection and fluid dynamics, IOP Conf. Ser. Mater. Sci. Eng. 228 (2017) 012013. doi:10.1088/1757-899X/228/1/012013. 
[8] R. C. Vogel, M. Levenson, F. R. Masten, Chemical engineering division research highlights, Tech. Rep. ANL-7020, Argonne National Laboratory (1965).

[9] R. C. Vogel, M. Levenson, J. H. Schraidt, J. Royal, Chemical engineering divison research highlights, Tech. Rep. ANL-7175, Argonne National Laboratory (1966).

[10] L. M. Ferris, M. A. Bredig, F. J. Smith, Equilibrium distribution of lithium and bismuth between liquid lithium-bismuth alloys and molten lithium chloride at $650-800^{\circ}$, J. Phys. Chem. 77 (19) (1973) 2351-2357. doi: 10.1021/j100638a018.

[11] E. J. Cairns, C. E. Crouthamel, A. K. Fischer, M. S. Foster, J. C. Hesson, C. E. Johnson, H. Shimotake, A. D. Tevebaugh, Galvanic Cells with Fused-Salt Electrolytes, Tech. Rep. ANL-7316, Argonne National Laboratory $(1967)$.

[12] S. Lawroski, R. C. Vogel, M. Levenson, V. H. Munnecke, Chemical engineering division research highlights, Tech. Rep. ANL-6766, Argonne National Laboratory (1963).

[13] H. L. Chum, R. A. Osteryoung, Review of Thermally Regenerative Electrochemical Cells, Solar Energy Research Institute, 1981.

[14] S. Lawroski, R. C. Vogel, M. Levenson, V. H. Munnecke, Chemical engineering summary report, Tech. Rep. ANL-6648, Argonne National Laboratory (1963).

[15] N. V. Temnogorova, I. G. Volfson, A. I. Demidov, A. G. Morachevskii, Use of anodic chronopoentiometry for determining diffusion coefficients in molten alloys, Elektrokhimiya 16 (1979) 419-421.

[16] A. V. Nikitin, A. I. Demidov, A. G. Morachevskii, Alloy formation at a liquid bismuth cathode in molten-salts, J. Appl. Chem. USSR 52 (8) (1979) 1786-1787. 
[17] M. S. Foster, S. E. Wood, C. E. Crouthamel, Thermodynamics of Binary Alloys. I. The Lithium-Bismuth System, Inorg. Chem. 3 (10) (1964) 14281431.

[18] S. Lawroski, R. C. Vogel, M. Levenson, V. H. Munnecke, Chemical engineering division summary report, Tech. Rep. ANL-6725, Argonne National Laboratory (1963).

[19] A. Demidov, A. G. Morachevskii, Thermodynamic properties of liquid lithium - bismuth alloys, Elektrokhimiya 9 (9) (1973) 1393-1394.

[20] W. Gasior, Z. Moser, W. Zakulski, Bi-Li System. Thermodynamic properties and the phase diagram calculations, Arch. Metall. 39 (4) (1994) $355-364$.

[21] H. Shimotake, G. L. Rogers, E. J. Cairns, Secondary Cells with Lithium Anodes and Immobilized Fused-Salt Electrolytes, Ind. Eng. Chem. Process Des. Dev. 8 (1) (1969) 51-56.

[22] D. A. J. Swinkels, Molten Salt Batteries and Fuel Cells, in: J. Braunstein, G. Mamantov, G. P. Smith (Eds.), Advances in Molten Salt Chemistry, Vol. 1, Plenum Press, New York, 1971, pp. 165-223.

[23] E. J. Cairns, R. K. Steunenberg, High-temperature batteries, in: C. Rouse (Ed.), Progress in High Temperature Physics and Chemistry, Vol. 5, Pergamon Press, 1973, pp. 63-124.

[24] P. Personnettaz, S. Landgraf, M. Nimtz, N. Weber, T. Weier, Mass transport induced asymmetry in charge/discharge behavior of liquid metal batteries, Electrochem. Commun. 105 (2019) 106496. doi:10.1016/j. elecom.2019.106496.

[25] D. H. Kelley, T. Weier, Fluid mechanics of liquid metal batteries, Appl. Mech. Rev. 70 (2) (2018) 020801. doi:10.1115/1.4038699. 
[26] O. Zikanov, Metal pad instabilities in liquid metal batteries, Phys. Rev. E 92 (2015) 063021.

[27] G. M. Horstmann, N. Weber, T. Weier, Coupling and stability of interfacial waves in liquid metal batteries, J. Fluid Mech. 845 (2018) 1-35. doi:10.1017/jfm.2018.223.

[28] N. Weber, P. Beckstein, W. Herreman, G. M. Horstmann, C. Nore, F. Stefani, T. Weier, Sloshing instability and electrolyte layer rupture in liquid metal batteries, Phys. Fluids 29 (5) (2017) 054101. doi: 10.1063/1.4982900.

[29] N. Weber, M. Nimtz, P. Personnettaz, A. Salas, T. Weier, Electromagnetically driven convection suitable for mass transfer enhancement in liquid metal batteries, Appl. Therm. Eng. 143 (2018) 293-301. doi: 10.1016/j . applthermaleng. 2018.07.067.

[30] P. Personnettaz, P. Beckstein, S. Landgraf, T. Köllner, M. Nimtz, N. Weber, T. Weier, Thermally driven convection in Li\$-\$Bi liquid metal batteries, J. Power Sources 401 (2018) 362-374. doi:10.1016/j . jpowsour.2018.08.069.

[31] M. Streb, Thermische Modellierung und Einsatzsimulation von Flüssigmetallbatterien, master thesis, Technische Universität Dresden, Dresden (2018).

[32] T. Köllner, T. Boeck, J. Schumacher, Thermal Rayleigh-Marangoni convection in a three-layer liquid-metal-battery model, Phys. Rev. E 95 (2017) 053114. doi:10.1103/PhysRevE.95.053114.

[33] S. A. Barriga, An electrochemical investigation of the chemical diffusivity in liquid metal alloys, Ph.D. thesis, Massachusetts Institute of Technology (2013).

[34] R. F. Ashour, D. H. Kelley, Convection-Diffusion Model of LithiumBismuth Liquid Metal Batteries, in: G. Lambotte, J. Lee, A. Al- 
lanore, S. Wagstaff (Eds.), Materials Processing Fundamentals 2018, Springer International Publishing, Cham, 2018, pp. 41-52. doi:10.1007/ 978-3-319-72131-6_4.

[35] R. F. Ashour, Tackling Key Engineering Challenges in Liquid Metal Batteries: Temperature and Mass Transport, Ph.D. thesis, University of Rochester, Rochester (2019).

[36] P. Personnettaz, S. Landgraf, M. Nimtz, N. Weber, T. Weier, Effects of current distribution on mass transport in the positive electrode of a liquid metal battery, Magnetohydrodynamics 56 (2/3) (2020) 247-254.

[37] P. Personnettaz, T. S. Klopper, N. Weber, T. Weier, Layer coupling between solutal and thermal convection in liquid metal batteries, Int. J. Heat Mass Transf. in press (2021).

[38] J. M. Newhouse, Modeling the Operating Voltage of Liquid Metal Battery Cells, Ph.D. thesis, Massachusetts Institute of Technology (2014).

[39] W. Herreman, S. Bénard, C. Nore, P. Personnettaz, L. Cappanera, J.-L. Guermond, Solutal buoyancy and electrovortex flow in liquid metal batteries, Phys. Rev. Fluids 5 (7) (2020) 074501. doi:10.1103/PhysRevFluids . 5.074501 .

[40] N. Weber, S. Landgraf, K. Mushtaq, M. Nimtz, P. Personnettaz, T. Weier, J. Zhao, D. Sadoway, Modeling discontinuous potential distributions using the finite volume method, and application to liquid metal batteries, Electrochimica Acta 318 (2019) 857-864. doi:10.1016/j.electacta.2019. 06.085.

[41] N. Weber, M. Nimtz, P. Personnettaz, T. Weier, D. Sadoway, Numerical simulation of mass transfer enhancement in liquid metal batteries by means of electro-vortex flow, J. Power Sources Adv. 1 (2020) 100004. doi:10.1016/j.powera. 2020.100004. 
[42] B. Predel, Bi-Li (Bismuth-Lithium), in: O. Madelung (Ed.), LandoltBörnstein - Group IV Physical Chemistry, Vol. 5B, Springer, Berlin Heidelberg, 1992.

[43] J. Sangster, A. D. Pelton, The Bi-Li (Bismuth-Lithium) system, J. Phase Equilibria 12 (4) (1991) 447-450. doi:10.1007/BF02645966.

[44] W. Weppner, Thermodynamic Properties of the Intermetallic Systems Lithium-Antimony and Lithium-Bismuth, J. Electrochem. Soc. 125 (1) (1978) 7. doi:10.1149/1.2131401.

[45] A. J. Bard, L. R. Faulkner, Electrochemical Methods: Fundamentals and Applications, 2nd Edition, Wiley, New York, 2001.

[46] J. Newman, K. E. Thomas-Alyea, Electrochemical Systems, John Wiley \& Sons, 2004.

[47] K. J. Vetter, Electrochemical Kinetics, Elsevier Science, Burlington, 1967.

[48] J. M. Newhouse, D. R. Sadoway, Charge-Transfer Kinetics of Alloying in Mg-Sb and Li-Bi Liquid Metal Electrodes, J. Electrochem. Soc. 164 (12) (2017) A2665-A2669.

[49] H. G. Weller, G. Tabor, H. Jasak, C. Fureby, A tensorial approach to computational continuum mechanics using object-oriented techniques, Comput. Phys. 12 (6) (1998) 620-631.

[50] A. Fick, Ueber Diffusion, Ann. Phys. 170 (1) (1855) 59-86. doi:10.1002/ andp. 18551700105.

[51] R. Levicky, Multicomponent Systems, Tech. rep., Tandon School of Engineering (2020).

[52] J. R. Welty, Fundamentals of Momentum, Heat and Mass Transfer, 6th Edition, Wiley, Hoboken, NJ, 2015. 
[53] H. S. Carslaw, J. C. Jaeger, Conduction of Heat in Solids, Clarendon Press, 1959.

[54] J. Crank, The Mathematics of Diffusion, 2nd Edition, Clarendon Press, Oxford, 1975.

[55] J. H. Ferziger, M. Perić, Numerische Strömungsmechanik, Springer, Berlin Heidelberg, 2008.

[56] G. Van Rossum, F. L. Drake, Python 3 Reference Manual, CreateSpace, Scotts Valley, CA, 2009.

[57] A. Oberbeck, Ueber die Wärmeleitung der Flüssigkeiten bei der Berücksichtigung der Strömungen infolge von Temperaturdifferenzen, Ann. Phys. 7 (1879) 271-292.

[58] J. Boussinesq, Théorie Analytique de La Chaleur, Gauthier-Villars, Paris, 1903.

[59] J. G. Kirkwood, R. L. Baldwin, P. J. Dunlop, L. J. Gosting, G. Kegeles, Flow Equations and Frames of Reference for Isothermal Diffusion in Liquids, J. Chem. Phys. 33 (5) (1960) 1505. doi:10.1063/1.1731433.

[60] P. Wendt, L. Gosting, The diffusion coefficient of lactamide in dilute aqueous solutions at $25^{\circ} \mathrm{C}$ as measured with the Gouy diffusiometer, J. Phys. Chem. 63 (1959) 1287-1291.

[61] J.-F. Dufrêche, O. Bernard, P. Turq, Transport equations for concentrated electrolyte solutions: Reference frame, mutual diffusion, J. Chem. Phys. 116 (5) (2002) 2085-2097. doi:10.1063/1.1427724.

[62] G. S. Hartley, J. Crank, Some fundamental definitions and concepts in diffusion processes, Trans. Faraday Soc. 45 (1949) 801. doi:10.1039/ tf9494500801. 
[63] V. Gekas, I. Lamberg, Determination of diffusion coefficients in volumechanging systems-Application in the case of potato drying, J. Food Eng. 14 (4) (1991) 317-326. doi :10.1016/0260-8774(91)90021-J.

[64] P. E. Viollaz, C. Suarez, An equation for diffusion in shrinking or swelling bodies, J. Polym. Sci. Polym. Phys. Ed. 22 (5) (1984) 875-879. doi: 10.1002/pol.1984.180220509.

[65] S. Alsoy, J. L. Duda, Influence of swelling and diffusion-induced convection on polymer sorption processes, AIChE J. 48 (9) (2002) 1849-1855. doi: 10.1002/aic. 690480903 .

[66] A. Blanchard, Enabling multi-cation electrolyte usage in LMBs for lower cost and operating temperature, bachelor thesis, Massachusetts Institute of Technology (2013).

[67] A. Redkin, Y. Zaikov, A. Dedyukhin, E. Nikolaeva, Electrical Conductivity of Molten Electrolytes with a Common Cation, J. Electrochem. Soc. 158 (12) (2011) F179-F182. doi:10.1149/2.028112jes.

[68] G. J. Janz, R. P. T. Tomkins, C. B. Allen, Molten Salts: Volume 4, Part 4 Mixed Halide Melts Electrical Conductance, Density, Viscosity, and Surface Tension Data, J. Phys. Chem. Ref. Data 8 (1) (1979) 125-302. doi: 10.1063/1.555590.

[69] R. C. Vogel, E. R. Proud, J. Royal, Chemical engineering division research highlights, Tech. Rep. ANL-7450, Argonne National Laboratory (1968).

[70] P. Masset, A. Henry, J.-Y. Poinso, J.-C. Poignet, Ionic conductivity measurements of molten iodide-based electrolytes, J. Power Sources 160 (1) (2006) 752-757. doi:10.1016/j.jpowsour.2006.01.014.

[71] S. Fujiwara, M. Inaba, A. Tasaka, New molten salt systems for hightemperature molten salt batteries: $\mathrm{LiF}-\mathrm{LiCl}-\mathrm{LiBr}-$ based quaternary systems, J. Power Sources 195 (22) (2010) 7691-7700. doi:10.1016/j. jpowsour.2010.05.032. 
[72] G. J. Janz, Thermodynamic and transport properties for molten salts: Correlation equations for critically evaluated density, surface tension, electrical conductance, and viscosity data, J. Phys. Chem. Ref. Data 17 (1988).

[73] G. J. Janz, R. P. T. Tomkins, C. B. Allen, J. R. Downey, G. L. Gardner, U. Krebs, S. K. Singer, Molten Salts: Volume 4, Part 2, Chlorides and Mixtures, J. Phys. Chem. Ref. Data 4 (1975) 871-1178. doi:doi.org/ $10.1063 / 1.555527$.

[74] E. R. van Artsdalen, I. S. Yaffe, Electrical conductance and density of molten salt systems: $\mathrm{KCl}-\mathrm{LiCl}, \mathrm{KCl}-\mathrm{NaCl}$ and $\mathrm{KCl}-\mathrm{KI}$, J. Phys. Chem. 59 (2) (1955) 118-127.

[75] C. J. Smithells, W. F. Gale, T. C. Totemeier, Smithells Metals Reference Book, eighth Edition, Elsevier Butterworth-Heinemann, Amsterdam, 2004 .

[76] L. Vegard, Die Konstitution der Mischkristalle und die Raumfüllung der Atome, Z. für Phys. 5 (1921) 17-26.

[77] C. Fazio, Handbook on Lead-bismuth Eutectic Alloy and Lead Properties, Materials Compatibility, Thermal-hydraulics and Technologies, Tech. Rep. 7268, Nuclear Energy Agency (2015).

[78] J. Brillo, Thermophysical Properties of Multicomponent Liquid Alloys, De Gruyter Oldenbourg, Berlin Boston, 2016.

[79] G. Steinleitner, W. Freyland, F. Hensel, Electrical conductivity and excess volume of the liquid alloy system Li-Bi, Berichte Bunsenges. für Phys. Chem. 79 (12) (1975) 1186-1189. doi:10.1002/bbpc.19750791204.

[80] J.-F. Wax, M. R. Johnson, L. E. Bove, M. Mihalkovič, Multiscale study of the influence of chemical order on the properties of liquid Li-Bi alloys, Phys. Rev. B 83 (14) (2011) 144203. doi:10.1103/PhysRevB.83.144203. 
[81] J. Hafner, A. Pasturel, P. Hicter, Chemical Short-Range Order in Liquid Li-Based Alloys, Z. für Met. 76 (1985) 432-439.

[82] J. Souto, M. M. G. Alemany, L. J. Gallego, L. E. González, D. J. González, Static structure, microscopic dynamics and electronic properties of the liquid Bi-Li alloy. An ab initio molecular dynamics study, Model. Simul. Mater. Sci. Eng. 21 (7) (2013) 075006. doi:10.1088/0965-0393/21/7/ 075006.

[83] L. E. Bove, F. Formisano, E. Guarini, A. Ivanov, C. Petrillo, F. Sacchetti, Evidence for the coexistence of two density fluctuation modes in molten $\mathrm{Li}_{30} \mathrm{Bi}_{70}$ as probed by neutron scattering, Europhys. Lett. EPL 79 (1) (2007) 16002. doi:10.1209/0295-5075/79/16002.

[84] J. D. van Norman, Anodic Chronopotentiometry at a Liquid Bismuth Electrode in Fused Lithium Chloride-Potassium Chloride, Anal. Chem. 33 (7) (1961) 946-948. doi:10.1021/ac60175a039.

[85] Y. Liu, Z. Kang, J. Wang, Thermodynamic basis and related phase equilibria for Bi-Li and Bi-Na binary systems, Thermochim. Acta 558 (2013) 53-60. doi:10.1016/j.tca.2013.01.029.

[86] M.-L. Saboungi, J. Marr, M. Blander, Thermodynamic properties of a quasi-ionic alloy from electromotive force measurements: The $\mathrm{Li}-\mathrm{Pb}$ system, J. Chem. Phys. 68 (4) (1978) 1375-1384. doi:10.1063/1.435957.

[87] Z. Cao, W. Xie, P. Chartrand, S. Wei, G. Du, Z. Qiao, Thermodynamic assessment of the Bi-alkali metal ( $\mathrm{Li}, \mathrm{Na}, \mathrm{K}, \mathrm{Rb}$ ) systems using the modified quasichemical model for the liquid phase, Calphad 46 (2014) 159-167. doi:10.1016/j.calphad.2014.04.001.

[88] C. E. Crouthamel, H. L. Recht (Eds.), Regenerative EMF Cells, Vol. 64, American Chemical Society, 1967. 
[89] Y. Wang, J. Zhang, Thermodynamic Properties of $\mathrm{K}$ and Li in Liquid Bismuth Determined by emf Measurements, J. Electrochem. Soc. 166 (13) (2019) D539-D545. doi:10.1149/2.0191913jes.

[90] S. Bénard, N. Weber, G. M. Horstmann, S. Landgraf, T. Weier, Anodemetal drop formation and detachment mechanisms in liquid metal batteries, J. Power Sources 210 (2021) 230339. doi:10.1016/j.jpowsour. 2021.230339 .

[91] V. Pavlyuk, M. Sozanskyi, G. Dmytriv, S. Indris, H. Ehrenberg, Amendment of the Li-Bi Phase Diagram Crystal and Electronic Structure of $\mathrm{Li}_{2} \mathrm{Bi}$, J. Phase Equilibria Diffus. 36 (6) (2015) 544-553. doi:10.1007/ s11669-015-0409-z.

[92] R. Berridge, Investigating the investment and operational costs of the Na-Zn molten salt battery and evaluating how cost competitive it will be against other technologies in the future, master thesis, Imperial College London (2021).

[93] V. T. Nguyen, J. E. Enderby, The electronic structure of lithium-based liquid semiconducting alloys, Philos. Mag. 35 (4) (1977) 1013-1019. doi: $10.1080 / 14786437708232641$.

[94] G. Grube, H. Voßkühler, H. Schlecht, Elektrische Leitfähigkeit und Zustandsdiagramm bei binären Legierungen, Z. für Elektrochem. 40 (5) (1934) $270-274$.

[95] R. P. Millere, V. I. Sharamkin, E. V. Shcherbinin, Effect of a longitudinal magnetic field on electrically driven rotational flow in a cylindrical vessel, Magn. Gidrodin. 1 (1980) 81-85.

[96] V. Bojarevičs, Y. Freibergs, E. I. Shilova, E. V. Shcherbinin, Electrically Induced Vortical Flows, Kluwer Academic Publishers, 1989.

[97] W. Herreman, C. Nore, P. Ziebell Ramos, L. Cappanera, J.-L. Guermond, N. Weber, Numerical simulation of electro-vortex flows in cylindrical fluid 
layers and liquid metal batteries, Phys. Rev. Fluids 4 (2019) 113702. doi: 10.1103/PhysRevFluids.4.113702.

[98] M. Abramowitz, I. A. Stegun (Eds.), Handbook of Mathematical Functions: With Formulas, Graphs, and Mathematical Tables, 9th Edition, Dover Books on Mathematics, Dover Publ., New York, NY, 2013.

[99] H. P. Langtangen, S. Linge, Finite Difference Computing with PDEs: A Modern Software Approach, Vol. 16 of Texts in Computational Science and Engineering, Springer International Publishing, Cham, 2017. doi: $10.1007 / 978-3-319-55456-3$.

[100] H. K. Versteeg, W. Malalasekera, An Introduction to Computational Fluid Dynamics. The Finite Volume Method, Pearson Education, 2007.

[101] R. Schwarze, CFD-Modellierung, Springer Berlin Heidelberg, Berlin, Heidelberg, 2013.

[102] F. Moukalled, L. Mangani, M. Darwish, The Finite Volume Method in Computational Fluid Dynamics, Springer International Publishing, Cham, 2016.

\section{Appendix A. Ohmic overpotential}

\section{Appendix A.1. Analytical solution for cylindrical geometries}

We calculate the potential distribution in the electrolyte for the left axisymmetric cylindrical cell shown in Figure 4. In reality, even the sidewalls of the negative electrode will be covered to a certain extend by molten salt. As the current path from these side walls to the positive electrode is much longer than from the bottom of the negative electrode, we assume that all current flows through the bottom of the metal foam only. Since the electrical current in the electrolyte can be uniquely described by a potential through Ohm's law $\boldsymbol{j}=-\sigma \boldsymbol{\nabla} \phi$ and must be closed $(\boldsymbol{\nabla} \cdot \boldsymbol{j})$, we need to solve the two-dimensional 
Laplace equation

$$
\Delta \phi=\frac{\partial^{2} \phi}{\partial r^{2}}+\frac{1}{r} \frac{\partial \phi}{\partial r}+\frac{\partial^{2} \phi}{\partial z^{2}}=0
$$

in the electrolyte's domain, where we have applied cylindrical coordinates $(r, \varphi, z)$ with the origin located in the centre of the salt-negative electrode interface. For the boundary conditions, we assume that the sidewalls between electrolyte and cell housing are perfectly insulating and that we have a homogeneous vertical current distribution in the positive electrode - for a comparison of different alternative boundary conditions, such as the Millere profile, see [95-97]. The boundary conditions read

$$
\begin{aligned}
& \left.\frac{\partial \phi}{\partial r}\right|_{r=R_{1}}=0 \\
& \left.\frac{\partial \phi}{\partial z}\right|_{z=-H}=\frac{I}{\sigma \pi R_{1}^{2}}, \\
& \left.\frac{\partial \phi}{\partial z}\right|_{z=0}=\frac{I}{\sigma \pi R_{2}^{2}} \Theta\left(R_{2}-r\right),
\end{aligned}
$$

where $I$ denotes the total cell current and $\Theta$ is the Heaviside function ensuring that no current bypasses the negative electrode in the region $r>R_{2}$. Please note that the current distribution is usually not homogeneous, in particular not in the negative electrode foam if its radius $R_{2}$ is considerably smaller than the cylinder radius $R_{1}$. However, we seek for an approximate solution of the cell voltage to be expressed analytically, requiring to keep the boundary conditions as simple as possible. This approximation is a posteriori justified in figure 5, where we discuss the relative error following from this approximation. The cylindrical boundary value problem (A.1) - (A.4) is solved by expanding a Fourier-Bessel series. We take the ansatz

$$
\phi=-\frac{I}{\sigma \pi R_{1}^{2}} z+\sum_{n=1}^{\infty} a_{n} \cosh \left(\frac{\epsilon_{0 n}}{R_{1}}(z+H)\right) J_{0}\left(\epsilon_{0 n} \frac{r}{R_{1}}\right),
$$

with $J_{0}$ being the zero-order Bessel function of the first kind and the numbers $\epsilon_{0 n}$ given as the $n$ roots of the first derivative of the zero-order Bessel function

$$
J_{0}^{\prime}\left(\epsilon_{0 n}\right)=0
$$


which can be easily determined numerically or found in, e.g. [98]. The coefficients $a_{n}$ are to be determined by applying condition (A.4); ansatz (A.5) already fulfils the simple boundary conditions (A.2) and (A.3). Inserting ansatz (A.5) into (A.4), multiplying both sides of the equation by $r J_{0}\left(\epsilon_{0 m} r / R_{1}\right)$ and eventually integrating the equation over the cylinder radius $R_{1}$, we find explicit expressions for the coefficient $a_{n}$ as

$$
a_{n}=\frac{2 I J_{1}\left(\epsilon_{0 n} \frac{R_{2}}{R_{1}}\right)}{\sigma \pi R_{2} \sinh \left(\frac{\epsilon_{0 n}}{R_{1}} H\right) \epsilon_{0 n}^{2} J_{0}^{2}\left(\epsilon_{0 n}\right)} .
$$

For the calculation, we have exploited the orthogonality condition

$$
\int_{0}^{R_{1}} r J_{0}\left(\epsilon_{0 m} \frac{r}{R_{1}}\right) J_{0}\left(\epsilon_{0 n} \frac{r}{R_{1}}\right) \mathrm{d} r=\frac{1}{2} R_{1}^{2} J_{0}^{2}\left(\epsilon_{0 n}\right) \delta_{m n} .
$$

Inserting (A.7) into (A.5) finally yields the potential solution

$$
\phi=-\frac{I}{\sigma \pi R_{1}^{2}} z-\sum_{n=1}^{\infty} \frac{2 I J_{1}\left(\epsilon_{0 n} \frac{R_{2}}{R_{1}}\right)}{\sigma \pi \epsilon_{0 n}^{2} R_{2}} \frac{\cosh \left(\frac{\epsilon_{0 n}}{R_{1}}(z+H)\right)}{\sinh \left(\frac{\epsilon_{0 n}}{R_{1}} H\right)} \frac{J_{0}\left(\epsilon_{0 n} \frac{r}{R_{1}}\right)}{J_{0}^{2}\left(\epsilon_{0 n}\right)} .
$$

The solution contains the voltage loss expected to occur in the electrolyte. It is defined as the potential difference between negative and positive electrode, but we must take into account that the potential is not constant along the negative electrode foam. To approximate the global cell voltage, we consider the mean potential in the negative electrode (the positive electrode potential is approximately constant), so that the voltage drop is given as

$$
\begin{aligned}
\eta_{\Omega} & :=\frac{1}{R_{2}} \int_{0}^{R_{2}} \phi(r, z=-H)-\phi(r, z=0) \mathrm{d} r \\
& =\frac{I H}{\sigma \pi R_{1}^{2}}+\sum_{n=1}^{\infty} \frac{I J_{1}\left(\kappa_{0 n}\right)}{\sigma \pi \epsilon_{0 n}^{2} R_{2}} \tanh \left(\frac{\epsilon_{0 n}}{R_{1}} \frac{H}{2}\right) \frac{\pi H_{0}\left(\kappa_{0 n}\right) J_{1}\left(\kappa_{0 n}\right)+\left(2-\pi H_{1}\left(\kappa_{0 n}\right)\right) J_{0}\left(\kappa_{0 n}\right)}{J_{0}^{2}\left(\epsilon_{0 n}\right)},
\end{aligned}
$$

with $\kappa_{0 n}=\epsilon_{0 n} R_{2} / R_{1}$. For the calculation we have applied the hyperbolic identity $\operatorname{coth}(x)-\sinh (x)^{-1}=\tanh (x / 2) . H_{0}$ and $H_{1}$ refer here to the Struve functions of zero and first order, see [98], which result from the integration of $J_{0}$. The first term in (A.10) describes the homogeneous voltage for the trivial 
case $R_{1}=R_{2}$. The following Fourier sums correct this solution to account for the inhomogeneities caused by the asymmetry of positive and negative electrode $R_{2}<R_{1}$. The convergence behaviour of the series strongly depends on the ratio $R_{2} / R_{1}$. For point-like negative electrodes $R_{2} \ll R_{1}$ the solution converges very slowly but correspondingly fast if the electrodes are in the same order. For all the practical cases shown in figure 5 it was sufficient to keep the first 400 terms allowing for a very fast calculation.

\section{Appendix A.2. Numerical solution for cylindrical geometries}

The voltage loss in the electrolyte of a cylindrical cell, as illustrated in figure 4 is

$$
\begin{aligned}
\eta_{\Omega}=I \frac{0.05^{2}}{\sigma R_{1}^{2}}(a & +a_{1} A+a_{2} A^{2}+a_{3} A^{3}+a_{4} A^{4}+a_{5} A^{5}+a_{6} A^{6} \\
& +b_{1} H+b_{2} H^{2}+b_{3} H^{3}+b_{4} H^{4}+b_{5} H^{5}+b_{6} H^{6} \\
& +d_{1} A H+d_{2}(A H)^{2}+d_{3}(A H)^{3}+d_{4}(A H)^{4}+d_{5}(A H)^{5} \\
& \left.+e_{1} H / A+e_{2} H^{2} / A+e_{3} H A^{2}+e_{4} A H^{2}+e_{5} A H^{3}\right),
\end{aligned}
$$

with the ratio of the radii defined as $A=R_{2} / R_{1}$ and

$$
\begin{aligned}
& a=12.5, a_{1}=-105, a_{2}=358, a_{3}=-652 a_{4}=676, a_{5}=-378, a_{6}=89, \\
& b_{1}=214, b_{2}=-5.8 \cdot 10^{4}, b_{3}=3.3 \cdot 10^{6}, b_{4}=-8 \cdot 10^{7}, b_{5}=1.3 \cdot 10^{9}, b_{6}=-2.8 \cdot 10^{9}, \\
& d_{1}=-1277, d_{2}=-4507, d_{3}=-4.3 \cdot 10^{6}, d_{4}=2.4 \cdot 10^{8}, d_{5}=-4.5 \cdot 10^{9}, \\
& e_{1}=419, e_{2}=-1.1 \cdot 10^{4}, e_{3}=691, e_{4}=9.6 \cdot 10^{4}, e_{5}=-2 \cdot 10^{7} .
\end{aligned}
$$

The formula is valid for $A>0.3$ and electrolyte layers thicker than $2.5 \mathrm{~mm}$. 
Appendix A.3. Numerical solution for rectangular geometries

The voltage loss in the electrolyte of a square cell, as illustrated in figure 4 is

$$
\begin{aligned}
\eta_{\Omega}=I \frac{0.05^{2}}{\sigma L_{1}^{2}}(a & +a_{1} A+a_{2} A^{2}+a_{3} A^{3}+a_{4} A^{4}+a_{5} A^{5}+a_{6} A^{6} \\
& +b_{1} H+b_{2} H^{2}+b_{3} H^{3}+b_{4} H^{4}+b_{5} H^{5}+b_{6} H^{6} \\
& +d_{1} A H+d_{2}(A H)^{2}+d_{3}(A H)^{3}+d_{4}(A H)^{4}+d_{5}(A H)^{5} \\
& \left.+e_{1} H / A+e_{2} H^{2} / A+e_{3} H A^{2}+e_{4} A H^{2}+e_{5} A H^{3}\right),
\end{aligned}
$$

with the ratio of the side lengths defined as $A=L_{2} / L_{1}$ and

$a=45.5, a_{1}=-383, a_{2}=1312, a_{3}=-2395 a_{4}=2485, a_{5}=-1390, a_{6}=326$,

$b_{1}=354, b_{2}=-1.6 \cdot 10^{5}, b_{3}=1 \cdot 10^{7}, b_{4}=-2.6 \cdot 10^{8}, b_{5}=4.2 \cdot 10^{9}, b_{6}=-1.3 \cdot 10^{10}$,

$d_{1}=-3384, d_{2}=3.9 \cdot 10^{4}, d_{3}=-1.4 \cdot 10^{7}, d_{4}=7.5 \cdot 10^{8}, d_{5}=-1.3 \cdot 10^{10}$,

$e_{1}=1393, e_{2}=-3.5 \cdot 10^{4}, e_{3}=1746, e_{4}=2.3 \cdot 10^{5}, e_{5}=-5.1 \cdot 10^{6}$.

The formula is valid for $A>0.2$ and electrolyte layers, which are at least $2 \mathrm{~mm}$ thick.

\section{Appendix B. Discretisation of the diffusion equation}

Appendix B.1. Finite difference method

Appendix B.1.1. Equation

The diffusion equation

$$
\frac{\partial c}{\partial t}=\nabla \cdot D \nabla c
$$

is discretised using central differencing and the implicit Euler method as [55] (see also [99])

$$
\frac{c^{t}-c^{t-1}}{\Delta t}=\frac{\left(D \frac{\partial c}{\partial z}\right)_{i+0.5}-\left(D \frac{\partial c}{\partial z}\right)_{i-0.5}}{0.5\left(z_{i+1}-z_{i-1}\right)}
$$

with $t$ denoting the time, $i$ the point-index and $z$ the coordinate running from bottom to top. The first derivatives are discretised as

$$
\left(D \frac{\partial c}{\partial z}\right)_{i+0.5}=\frac{D_{i}+D_{i+1}}{2} \cdot \frac{c_{i+1}-c_{i}}{z_{i+1}-z_{i}}
$$


and

$$
\left(D \frac{\partial c}{\partial z}\right)_{i-0.5}=\frac{D_{i-1}+D_{i}}{2} \cdot \frac{c_{i}-c_{i-1}}{z_{i}-z_{i-1}}
$$

Combining these equations leads to

$$
c^{t}=\frac{\frac{D_{i}+D_{i+1}}{2} \cdot \frac{c_{i+1}-c_{i}}{z_{i+1}-z_{i}}-\frac{D_{i-1}+D_{i}}{2} \cdot \frac{c_{i}-c_{i-1}}{z_{i}-z_{i-1}}}{0.5\left(z_{i+1}-z_{i-1}\right)} \Delta t+c^{t-1}
$$

and after further simplification to

$c^{t}=\frac{\frac{D_{i}+D_{i+1}}{2} \cdot\left(c_{i+1}-c_{i}\right) \cdot\left(z_{i}-z_{i-1}\right)-\frac{D_{i-1}+D_{i}}{2} \cdot\left(c_{i}-c_{i-1}\right) \cdot\left(z_{i+1}-z_{i}\right)}{0.5\left(z_{i+1}-z_{i-1}\right) \cdot\left(z_{i+1}-z_{i}\right) \cdot\left(z_{i}-z_{i-1}\right)} \Delta t+c^{t-1}$

and finally to

$$
\begin{aligned}
c^{t} & =c_{i-1} \cdot \frac{\frac{D_{i-1}+D_{i}}{2} \cdot\left(z_{i+1}-z_{i}\right)}{0.5\left(z_{i+1}-z_{i-1}\right) \cdot\left(z_{i+1}-z_{i}\right) \cdot\left(z_{i}-z_{i-1}\right)} \Delta t \\
& +c_{i} \cdot \frac{-\frac{D_{i}+D_{i+1}}{2} \cdot\left(z_{i}-z_{i-1}\right)-\frac{D_{i-1}+D_{i}}{2} \cdot\left(z_{i+1}-z_{i}\right)}{0.5\left(z_{i+1}-z_{i-1}\right) \cdot\left(z_{i+1}-z_{i}\right) \cdot\left(z_{i}-z_{i-1}\right)} \Delta t \\
& +c_{i+1} \cdot \frac{\frac{D_{i}+D_{i+1}}{2} \cdot\left(z_{i}-z_{i-1}\right)}{0.5\left(z_{i+1}-z_{i-1}\right) \cdot\left(z_{i+1}-z_{i}\right) \cdot\left(z_{i}-z_{i-1}\right)} \Delta t \\
& +c^{t-1} .
\end{aligned}
$$

The equation is simplified by setting $c^{t}=c_{i}$, defining

$$
a=\frac{\Delta t}{\left(x_{i+1}-x_{i-1}\right) \cdot\left(x_{i+1}-x_{i}\right) \cdot\left(x_{i}-x_{i-1}\right)}
$$

and rearranging to fit to the matrix equation

$$
A \cdot c=b,
$$

which leads to

$$
\begin{aligned}
& c_{i-1} \cdot-\left(D_{i-1}+D_{i}\right) \cdot\left(z_{i+1}-z_{i}\right) \cdot a \\
& +c_{i}\left(1+\cdot\left(\left(D_{i}+D_{i+1}\right) \cdot\left(z_{i}-z_{i-1}\right)+\left(D_{i-1}+D_{i}\right) \cdot\left(z_{i+1}-z_{i}\right)\right) \cdot a\right) \\
& +c_{i+1} \cdot-\left(D_{i}+D_{i+1}\right) \cdot\left(z_{i}-z_{i-1}\right) \cdot a \\
& =c^{t-1} .
\end{aligned}
$$

We now define the upper distance

$$
d z_{u}=z_{i+1}-z_{i}
$$


and lower distance

$$
d z_{l}=z_{i}-z_{i-1}
$$

and

$$
d z_{u}+d z_{l}=z_{i+1}-z_{i-1}
$$

This gives

$$
a=\frac{\Delta t}{\left(d z_{u}+d z_{l}\right) d z_{u} d z_{l}},
$$

which leads to

$$
\begin{aligned}
& c_{i-1} \cdot-\left(D_{i-1}+D_{i}\right) \cdot d x_{u} \cdot a \\
& +c_{i} \cdot\left(1+\left(\left(D_{i}+D_{i+1}\right) \cdot d x_{l}+\left(D_{i-1}+D_{i}\right) \cdot d x_{u}\right) \cdot a\right) \\
& +c_{i+1} \cdot-\left(D_{i}+D_{i+1}\right) \cdot d x_{l} \cdot a \\
& =c^{t-1} .
\end{aligned}
$$

\section{Appendix B.1.2. Boundary conditions}

The boundary condition at the lower interface reads

$$
\nabla c \cdot \boldsymbol{n}=0=-c_{1}+c_{0}
$$

which leads to the coefficients $A[0,0]=1, A[0,1]=-1$ and $b=0$.

The boundary condition at the upper interface reads

$$
\nabla c \cdot \boldsymbol{n}=\frac{j}{\nu_{e} F D} .
$$

This Neumann boundary condition is discretised as [55]

$$
\nabla c=\frac{-c_{3}\left(z_{2}-z_{1}\right)^{2}+c_{2}\left(z_{3}-z_{1}\right)^{2}-c_{1}\left(\left(z_{3}-z_{1}\right)^{2}-\left(z_{2}-z_{1}\right)^{2}\right)}{\left(z_{2}-z_{1}\right)\left(z_{3}-z_{1}\right)\left(z_{3}-z_{2}\right)} .
$$

As $i$ counts from the bottom, we denote the last point by -1 , the second last point by -2 and so on, and find

$\nabla c=\frac{-c_{-3}\left(z_{-2}-z_{-1}\right)^{2}+c_{-2}\left(z_{-3}-z_{-1}\right)^{2}-c_{-1}\left(\left(z_{-3}-z_{-1}\right)^{2}-\left(z_{-2}-z_{-1}\right)^{2}\right)}{\left(z_{-2}-z_{-1}\right)\left(z_{-3}-z_{-1}\right)\left(z_{-3}-z_{-2}\right)}$.

We obtain the matrix coefficients as

$$
b=\frac{j}{\nu_{e} F D}
$$


and

$$
\begin{aligned}
& A[-1,-3]=-\left(z_{-2}-z_{-1}\right)^{2} / a \\
& A[-1,-2]=\left(z_{-3}-z_{-1}\right)^{2} / a \\
& A[-1,-1]=-\left(\left(z_{-3}-z_{-1}\right)^{2}-\left(z_{-2}-z_{-1}\right)^{2}\right) / a
\end{aligned}
$$

with

$$
a=\left(z_{-2}-z_{-1}\right)\left(z_{-3}-z_{-1}\right)\left(z_{-3}-z_{-2}\right) .
$$

Appendix B.1.3. Volume change

Volume change is accounted for by adjusting in each time step the distance between the points $d z$ (representing the volume) and rescaling the concentration appropriately. As the concentration is defined at the discretisation points, but the volume in between these points, two differently located scaling factors will be used.

As the first step, the initial masses $m$ are computed both, at and between the discretisation points. After solving the diffusion equation, the mass fluxes of $\mathrm{Li}, \dot{m}$, are calculated at and between the points. This way, the exact masses are obtained in each time step as

$$
m=m_{t-1}+\dot{m} \Delta t
$$

with $t-1$ denoting the previous time step. The masses are used to calculate the volume as

$$
V=m / \rho
$$

with the concentration-dependent density obtained from equation (35). The volumetric correction factor is then simply defined as

$$
f=V / V_{t-1}
$$

and is used to scale the distances between the discretisation points as

$$
d z=f \cdot d z_{t-1} .
$$


Due to the fact that the amount of moles of Li stays constant during this increase in volume, the molar concentration $c$ needs to be divided by the same factor. As the concentration is defined at the discretisation points, a similar factor is computed there. To stabilise the solution, it is sometimes useful to perform the volume change operation only every $\mathrm{n}^{\text {th }}$ iteration.

Appendix B.2. Finite volume method

Appendix B.2.1. Equation

The diffusion equation

$$
\frac{\partial c}{\partial t}=\nabla \cdot D \nabla c
$$

is discretised using the finite volume method as [55, 100-102]

$$
\frac{\partial}{\partial t} \int_{V} c d V=\int_{V} \nabla \cdot(D \nabla c) d V
$$

Using the implicit Euler method and the discretized form of the Gauss theorem, we obtain

$$
\frac{(c V)^{t}-(c V)^{t-1}}{\Delta t}=\sum_{f} D_{f} \boldsymbol{S}_{f} \cdot(\nabla c)_{f}=\sum_{f} D_{f}\left|S_{f}\right| \frac{c_{N}-c_{P}}{d}
$$

with $V$ denoting the volume of the control volume, $D_{f}$ the diffusivity on the faces, $\boldsymbol{S}_{f}$ the surface area vector, $d$ the distance between two cell centres, $c_{P}$ the concentration in the parent cell and $c_{N}$ the concentration in the neighbour cell. By dividing the equation by the surface area and introducing the cell height $d z$ we obtain

$$
c^{t}=\sum_{f} D_{f} \frac{c_{N}-c_{P}}{d} \frac{\Delta t}{d z^{t}}+\frac{c^{t-1} d z^{t-1}}{d z^{t}} .
$$

Denoting the concentration in the lower cell by $c_{i-1}$ and the one in the upper cell by $c_{i+1}, c_{N}$ is replaced. Further, we denote the distance of the parent cell centre to the lower cell by $d_{l}$ and the distance to the upper cell as $d_{u}$ and set $c^{t}=c_{i}$. We obtain the discretised equation in the matrix-form

$$
A \cdot c=b,
$$


as

$$
c_{i-1}\left(D_{f} \frac{\Delta t}{d_{l} d z^{t}}\right)+c_{i}\left(-1-\frac{D \Delta t}{d_{l} d z^{t}}-\frac{D_{f} \Delta t}{d_{u} d z^{t}}\right)+c_{i+1}\left(\frac{D_{f} \Delta t}{d_{u} d z^{t}}\right)=-\frac{c^{t-1} d z^{t-1}}{d z^{t}}
$$

Assuming no volume change at small time steps, we can assume $d z^{t} \approx d z^{t-1}$.

\section{Appendix B.2.2. Boundary conditions}

The boundary condition at the lower interface reads

$$
\nabla c \cdot \boldsymbol{n}=0=-c_{1}+c_{0},
$$

which means basically that the flux over the lower interface needs to be set to zero. This leads to a modification of the coefficients as $A[0,0]=-1-\frac{D_{f} \Delta t}{d_{u} d z^{t}}$. Similarly, the boundary condition on the top interface

$$
\nabla c \cdot \boldsymbol{n}=\frac{j}{\nu_{e} F D}
$$

requires a constant (given) flux through the upper interface, leading to a modified source term as

$$
b[-1]=-\frac{c^{t-1} d z^{t-1}}{d z^{t}}-\frac{j \Delta t}{\nu_{e} F d z^{t}}
$$

and a modified diagonal coefficient as

$$
A[-1,-1]=-1-\frac{D_{f} \Delta t}{d_{l} d z^{t}} .
$$

\section{Appendix B.2.3. Volume change}

Likewise to the finite difference method, the cell volume and concentration are scaled in each time step to account for volume change. However, here only one scaling factor is needed as concentration and volume are both defined in the cell centre of the control volumes. 